\title{
Price Discontinuities in an Online Market for Used Cars*
}

\author{
Florian Englmaier ${ }^{\dagger}$
}

\author{
Arno Schmöller
}

Till Stowasser ${ }^{\S}$

\author{
June 7, 2016
}

\begin{abstract}
We study the price-setting behavior in a competitive market for used cars and provide empirical evidence for coarse information processing. Based on detailed field data from one of Europe's largest online marketplaces for automotive vehicles, we document systematic and sizable price discontinuities at salient car-age and mileage thresholds. The price difference between two otherwise identical cars across registration years (where one was first registered in January and the other in December of the previous year) is up to five times larger than that between two cars first registered in any two subsequent months within a registration year. A similar pattern can be observed in the mileage dimension at 10,000-km odometer marks, which is in line with earlier findings by Lacetera et al. (2012). Being able to study discontinuities along two dimensions of the same good allows us to further our understanding towards a more general notion of inattentive behavior. While our results are compatible with a behavioral model of limited attention, we also provide evidence for a more traditional explanation based on search frictions.
\end{abstract}

Keywords: Price discontinuities, inattention, bounded rationality, information neglect, heuristics, search frictions, search cost, internet markets.

JEL classification: D12, D83, L62

\footnotetext{
${ }^{*}$ We are grateful to Anton Vasilev for his invaluable support during data collection. We thank participants at the 2013 IIOC conference in Boston, the 2013 VfS Meeting in Düsseldorf, the 2014 German IO comittee meeting in Hamburg, and in particular Maximilian Breu, Matthias Dischinger, Thomas Fackler, Nicola Lacetera, Devin Pope, Stephen Ryan, Klaus Schmidt, Peter Schwardmann, Justin Sydnor, and Steve Tadelis for their helpful comments and suggestions. Ines Helm provided excellent research assistance. This research was partially funded through DFG grant SFB/TR-15.

†University of Munich (LMU), florian.englmaier@econ.lmu.de

¥TWS Partners, info@schmoeller.org

${ }^{\S}$ University of Munich (LMU), till.stowasser@econ.lmu.de
} 


\section{Introduction}

Economic theory suggests that a rational agent should incorporate all relevant information when making a decision. However, at least since Simon (1955), economists have proposed models that relax this strong assumption. In these models, individuals simplify complex decisions, for example, by processing only a subset of information. Moreover, recent empirical research convincingly documents that consumers fail to efficiently process available information and instead rely on heuristic evaluation rules. ${ }^{1}$ In particular, Lacetera et al. (2012) analyze data from US used-car auctions, find systematic and substantial price drops at 10,000-mile odometer marks, and explain this pattern with a model of inattention based on left-digit bias (the tendency to focus on the left-most digit of a number and partially ignoring other digits). ${ }^{2}$

We use comprehensive field data on used-car offers from the German website mobile.de, one of Europe's largest online marketplaces for automotive vehicles, and are able to replicate the Lacetera et al. (2012) findings. But the German context allows for an additional line of inquiry, which helps us to gain a better understanding of the mechanism driving our results: In Germany, cars have an official and legally mandated documentation record that makes the year (or "vintage") and the month of first registration verifiable information. ${ }^{3}$ Importantly, the US "model-year" concept is neither used for German cars nor the German market as a whole. ${ }^{4}$ Instead of issuing (or advertising) a new model each year, German manufacturers produce a given model generation without significant changes for a period of several years. Hence, our dataset provides the unique opportunity to study a second dimension of coarse information processing within the same decision problem.

We find strong threshold effects on prices at first-registration-year changes. All else equal, the price differential between two cars, across vintages (where one car was first registered in January and the other in December of the previous year) is up to five times larger than that between two cars first registered in any two subsequent months within the same vintage. We document our results by implementing a regression-discontinuity design and by performing various robustness and placebo tests. A linear approximation of a limited-attention model in the spirit of DellaVigna (2009) and Lacetera et al. (2012) suggests that the inattention parameter - capturing

\footnotetext{
${ }^{1}$ See, among others, Malmendier and Lee (2011) and Brown et al. (2010) on internet auctions, or Chetty et al. (2009) and Finkelstein (2009) on taxes and tolls.

${ }^{2}$ For example, cars with odometer values between 59,000 and 59,999 miles are sold only slightly cheaper than cars with odometer readings between 58,000 and 58,999 miles, whereas the price drop to the $60,000-60,999$ miles bin is substantially larger.

${ }^{3}$ The official notation states the month first and the vintage second, divided by a forward slash. For instance, a car first registered on April 24th, 2016 would be labeled as 04/2016.

${ }^{4} \mathrm{~A}$ model-year concept would have confounded our analysis, given its inherent salience of the registration year where, say, the "New 2016 Toyota Corolla" would be advertised on billboards, TV spots, and magazine ads.
} 
the discontinuous price drops at thresholds - lies in the neighborhood of 0.3 to 0.4 for both dimensions, which is well within the range of parameter estimates documented in the literature.

While our results build on existing work on mileage discontinuities, we provide new evidence for the effects of inattention in another dimension, namely product age, which is applicable to a broader set of situations than odometer readings. In addition, both product dimensions differ with respect to their endogeneity, which generates contrasting predictions about the incidence of manipulative sorting: The date of first registration is an innate and unalterable feature of a used car, whereas its mileage can be strategically influenced by varying the date it is put up for sale. ${ }^{5}$ As a consequence, we should only expect anomalous bunching of car offers around salient thresholds in the mileage, but not in the vintage dimension. Moreover, studying discontinuities along two dimensions of the same good allows us to further our understanding towards a more general notion of inattention: Such a framework would be readily applicable to a wide set of domains where underlying continuous characteristics are mapped into discrete categories (such as classifications of French wine, star-based reviews of hotels, or ratings of financial assets) and for which "inefficient" price discontinuities might also exist.

The paramount role of information provision in online markets is underlined by Lewis (2011). Tadelis and Zettelmeyer (2015) document it for the used-car market also studied by Lacetera et al. (2012). Busse et al. (2013) add to the insights from the wholesale market studied in Lacetera et al. (2012) and document that price drops at 10,000-mile odometer thresholds are also prevalent for retail consumers. They argue that effects are driven by consumers who devote too little attention to evaluating vehicle mileage. Limited attention has also been documented for purchase decisions in other markets. For instance, Malmendier and Lee (2011) analyze individual bidding behavior in auctions on eBay and find that people tend to anchor on an irrelevant retail price for a board game if the seller mentions that price in the product description. At the same time, many of the winning bids exceed a more relevant outside option, the so-called "buy-it-now" price, which is a fixed strike price set by the seller as an alternative to the auction process. ${ }^{6}$ Pope (2009) shows that patients strongly react to changes in coarse rankings of hospitals while ignoring more informative continuous measures of hospital quality. In a similar vein, the degree of salience of taxes appears

\footnotetext{
${ }^{5}$ Note that while the date of first registration is an exogenous feature when selling a used car, it is certainly endogenous to the initial purchase decision when the car was new. We discuss this issue in Section 3.1.

${ }^{6}$ Schneider (2016) offers a follow-up comment on Malmendier and Lee (2011) and suggests that their results are potentially driven not by limited attention but by specific features of eBay's search filters that do not necessarily return all relevant alternatives for a specific good. As a result, auction prices may exceed fixed prices because consumers are simply unaware that the fixed-price option is available for the item in question.
} 
to affect consumption behavior. For example, Chetty et al. (2009) conduct a field experiment at a grocery store and find that posting tax-inclusive prices reduces demand. Finkelstein (2009) shows that reduced salience of road tolls (caused by the introduction of electronic toll-collection systems) leads to higher tolls. Analyzing stock market data, Gilbert et al. (2012) provide evidence that investors with limited attention have an incentive to focus on summary statistics rather than individual pieces of information. They analyze the market response to the U.S. Leading Economic Index (LEI), a macroeconomic release that is purely a summary statistic, and show that the LEI announcement has an impact on aggregate stock returns, return volatility, and trading volume. In a recent article, Luca (2016) studies consumer demand for restaurants and documents discontinuous responses to online ratings. We add to these findings by demonstrating that inattention affects high-stake purchase decisions even if the relevant information is readily available at basically no cost and by being able to study discontinuities along two dimensions of the same good.

The remainder of this paper is structured as follows. Section 2 describes the data. Section 3 presents the graphical and regression analysis for vintage and mileage discontinuities. An extensive set of robustness and placebo tests is summarized in Section 4. Section 5 discusses the implications of our results and concludes.

\section{Data}

\subsection{Data source: The mobile.de website}

We collected detailed information on more than 63,000 cars offered during July and August of 2009 on mobile.de, one of Europe's largest online marketplaces for automotive vehicles. Founded in 1996, mobile.de takes the role of an intermediary between supply and demand within a two-sided market. It provides a platform for sellers to place advertisements for new and used cars in exchange for a fixed fee, and it provides a free comprehensive search tool for prospective buyers to screen through roughly 1.5 million total offers. The company itself is not involved in the purchase or the sale of a vehicle and a successful transaction does not invoke any fees.

To borrow from mobile.de's self description, prospective buyers "can limit search results by setting individual preferences and like this obtain customized offers with just a few clicks", providing them "with an overview of the market and information about prices". ${ }^{7}$ The same is true for sellers who want to evaluate their car before offering it for sale.

Figure 1 shows the interface on mobile.de's main page. It is a simplified search form that allows to filter for makes, models, and a number of other basic characteristics. An advanced search form provides a large additional set of filter options. Conducting

\footnotetext{
${ }^{7}$ Source: http://cms.mobile.de/en/company/portrait_mobile.html; last accessed: April 24th, 2016
} 
Figure 1. Main page - www.mobile.de

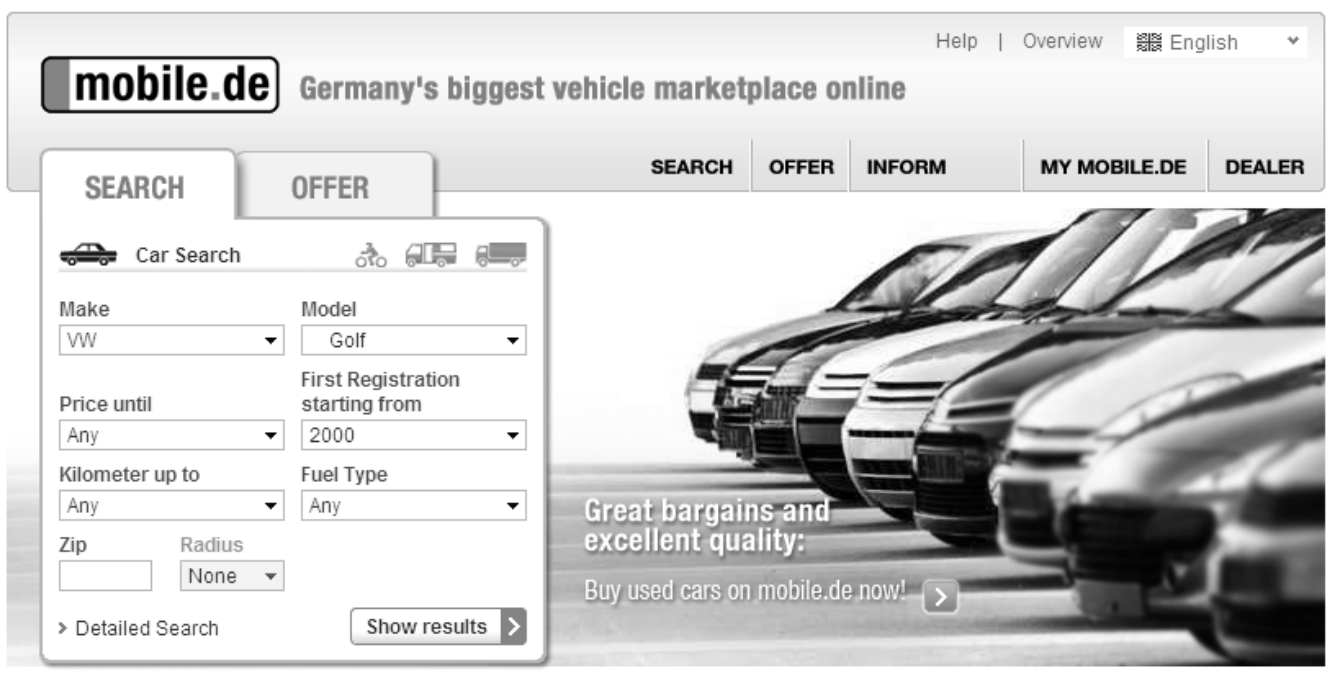

Figure 2. List of search results - www.mobile.de
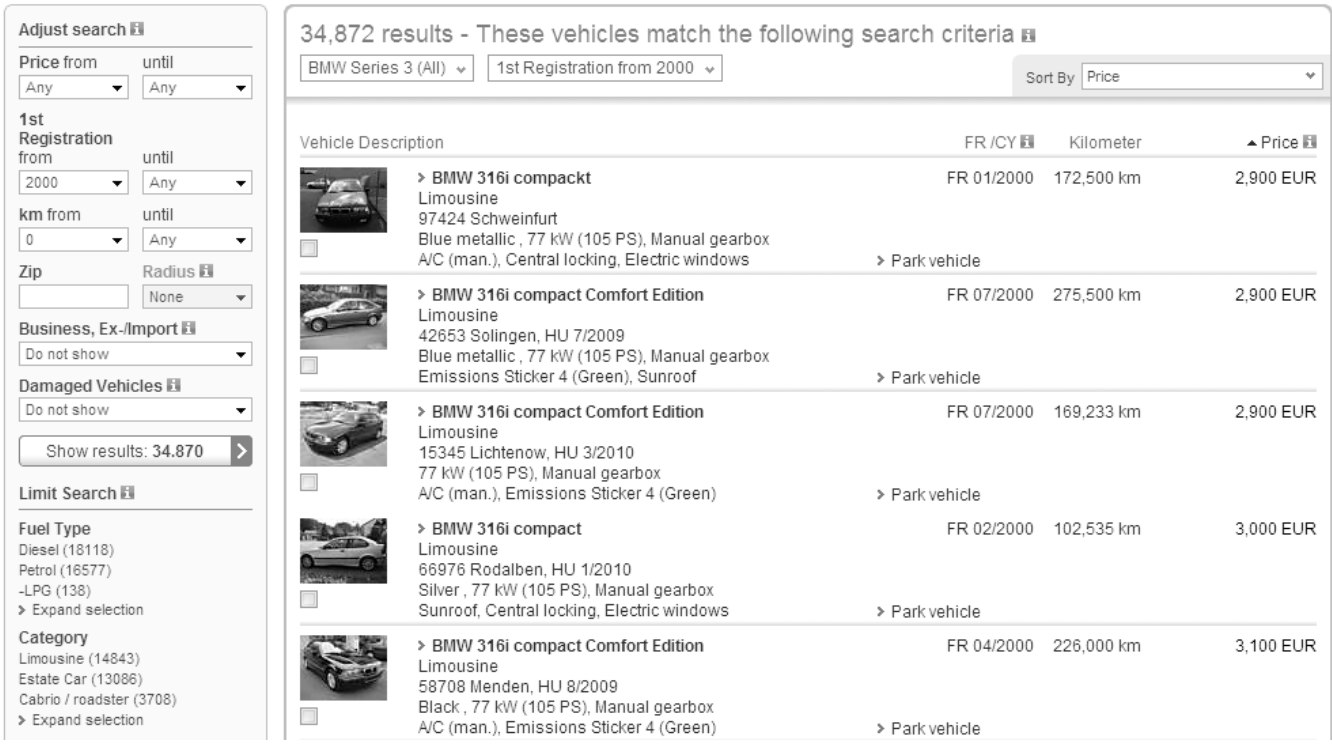

either type of a search, returns a list of all vehicles that match the chosen filters. By default, the search results are sorted by price, and their main attributes are summarized as shown in Figure 2. This preview explicitly states the first-registration date (e.g. "04/2016", if the car was first registered in April of 2016) besides additional information on price, mileage, color, motor power, and some additional features. It is also possible to save a specific car for later access (to "park" a vehicle), and to directly compare it to other selected cars. Figure 3 depicts an example profile page for a car offer, which is accessed by clicking the respective search result.

Since mobile.de is not an auction market, we only observe the asking prices of sellers. These may deviate from final prices due to negotiations during the actual sale of the car. However, for this to be a concern for our analysis, these deviations would have to systematically differ between pre- and post-threshold cars, which seems im- 
Figure 3. Car details - www.mobile.de

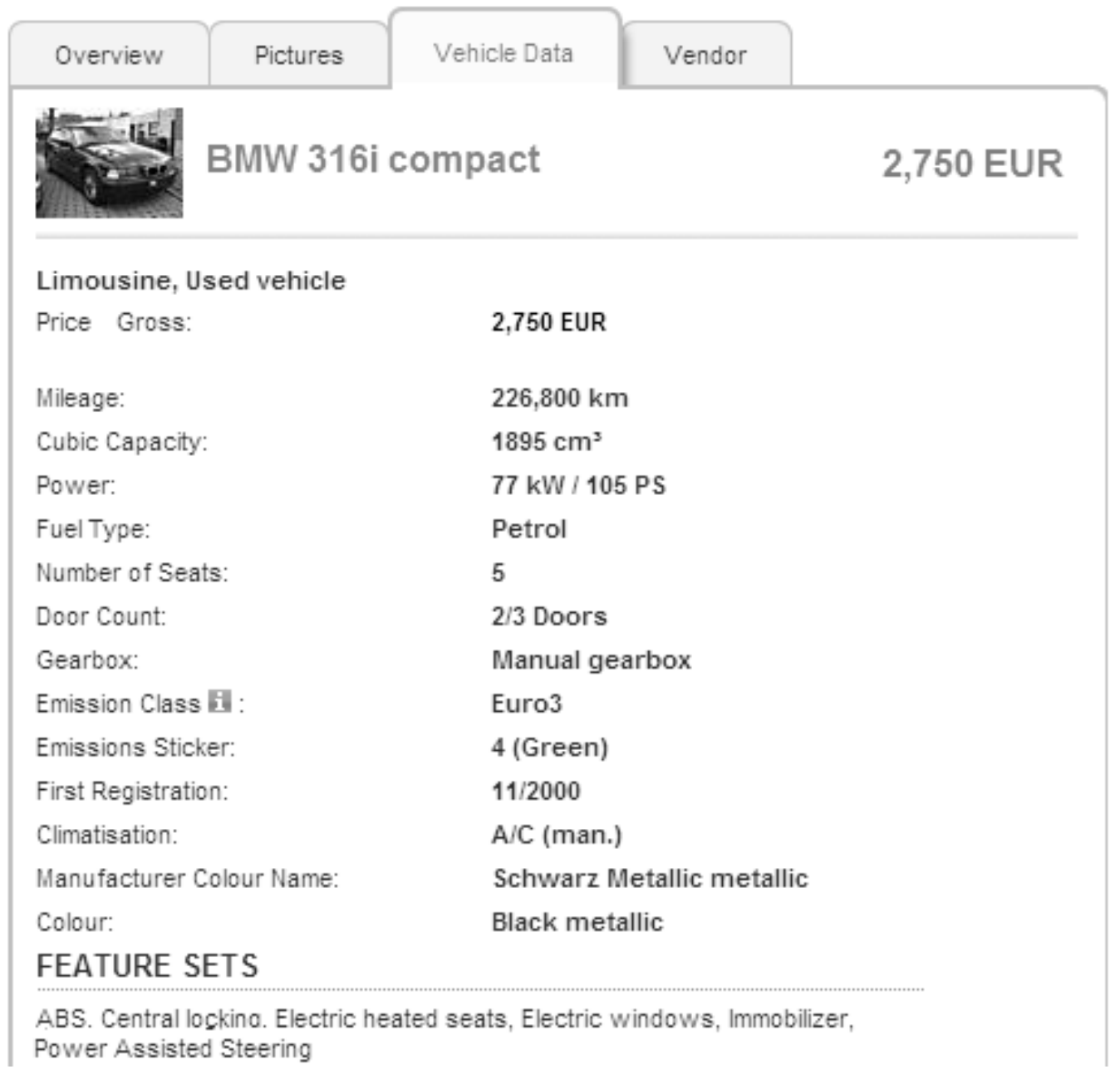

plausible. Nevertheless, we took two steps to validate that the asking price is indeed a reasonable proxy for the final price in this market environment: First, on mobile.de sellers have the option to declare the asking price as either "fixed" or "negotiable". For our analysis, we exclusively collected data from offers with fixed prices. Second, we extensively searched the web for guides on "how to buy a used car" or "how to negotiate a good deal when buying a used car". While there is an abundance of such handbooks, there is no mention of inflated prices (and bargaining opportunities) for January cars or that December cars are generally better deals. We regard the notable absence of such suggestions to be supportive of our argument. For simplicity, we use the terms "price" and "asking price" interchangeably throughout the paper.

\subsection{Sample composition}

Due to scarce resources during data collection, we limited our sample to the bestselling car model by each of the five leading German manufacturers. The five chosen models are also among the top ten of Germany's overall vehicle population according 
to the Federal Office for Motor Vehicles (Kraftfahrtbundesamt/KBA). ${ }^{8}$ Specifically, we collected information on 14,780 Volkswagen (VW) Golf (KBA-rank 1), 10,841 Opel Astra (KBA rank 2), 18,470 BMW 3 series (KBA rank 4), 14,219 Audi A4 (KBA rank 7), and 5,030 Mercedes Class A (KBA rank 9). ${ }^{9}$

We selected cars whose date of first registration falls between December 2007 and January 2000. Having collected the data in the summer of 2009, this implies that the youngest car in our sample is 20 months old, whereas the oldest car has an age of 116 months (roughly nine and a half years). This selection guarantees the exclusion of a particular market segment with quite idiosyncratic features, known as "Jahreswagen". Such cars are typically given to employees for roughly one year as part of their compensation package and differ substantially (both with respect to their characteristics and the way they were used) from privately owned vehicles that dominate the used-car market. ${ }^{10}$

Because the introduction of a new model generation affects prices substantially, we control for such model revisions. Information on the exact dates of the respective market launches are available through the so-called Schwacke list, the Deutsche Automobil Treuhand (DAT), and the manufacturers' websites. For an overview of model updates that occurred in our sample, see Table A.1 in Appendix A, and note that model updates do not happen around year changes in our sample. However, controlling for model revisions is not trivial because we only know when factories switched production from one generation to the next but cannot distinguish if a given car in our sample is in fact the new model or rather the previous one that has been sitting at the dealer's lot for a few months. For our main specifications, we classify a car as having undergone a model update if it was first registered more than three months after the factories switched production. In Section 4 we document that our results are robust to alternative definitions of these model-generation indicators.

\subsection{Summary statistics}

Table 1 provides the summary statistics of the main variables used for analysis. These include a whole roster of car features that will likely affect the seller's asking price. The two most important determinants for our analysis are a car's age and mileage. The age of a car is measured in months and normalized relative to the youngest

\footnotetext{
${ }^{8}$ Source: http://www.kba.de.

${ }^{9} \mathrm{KBA}$ ranks not reported were either held by non-German automakers or by other models of VW (Passat, Polo) and Opel (Corsa).

${ }^{10}$ This Jahreswagen option is particularly attractive in Germany because of its tax-preferred status, which makes it a hidden subsidy to the car industry. Results - which are available upon request - that include Jahreswagen show that our general results remain stable while discontinuities are unsystematic for this market segment.
} 
Table 1. Summary statistics of key variables

\begin{tabular}{lccccc}
\hline Variable & $\mathrm{N}$ & Mean & St. Dev. & Min & Max \\
\hline Price (in EUR) & 63,340 & 13,209 & 5,909 & 1,750 & 48,890 \\
Car age (in months) & 63,340 & 39.14 & 25.82 & 1 & 96 \\
Mileage (in km) & 63,340 & 87,338 & 51,629 & 1,000 & $1,499,000$ \\
Horsepower (in PS) & 63,289 & 97.26 & 28.94 & 44 & 309 \\
Indicator variables: & & & & & \\
- Diesel engine & 63,322 & 0.58 & 0.49 & 0 & 1 \\
- Automatic transmission & 63,018 & 0.21 & 0.40 & 0 & 1 \\
- Metallic paint & 63,340 & 0.79 & 0.41 & 0 & 1 \\
- Air conditioning & 63,340 & 0.97 & 0.17 & 0 & 1 \\
- Leather trim & 63,340 & 0.16 & 0.37 & 0 & 1 \\
- Airbag & 63,340 & 0.49 & 0.50 & 0 & 1 \\
- Power windows & 63,340 & 0.96 & 0.21 & 0 & 1 \\
- Sunroof & 63,340 & 0.18 & 0.38 & 0 & 1 \\
- Four-wheel drive & 63,340 & 0.05 & 0.22 & 0 & 1 \\
- Seat heating & 63,340 & 0.45 & 0.50 & 0 & 1 \\
- Cruise control & 63,340 & 0.43 & 0.50 & 0 & 1 \\
- Private seller & 63,340 & 0.13 & 0.34 & 0 & 1
\end{tabular}

Notes: Car age is measured relative to December 2007. N denotes the number of observations, St. Dev. stands for standard deviation, Min and Max are the minimum and the maximum value for each variable, respectively.

car in the sample. ${ }^{11}$ Additional car characteristics that are useful as control variables include engine power and several special features for which we define indicator variables. The final row of Table 1 indicates that roughly $87 \%$ of offers come from professional car dealers.

Unconditional correlations between these variables are in line with conventional wisdom: Car prices are strongly negatively correlated with car age $(\rho=-0.85)$ and with mileage $(\rho=-0.78)$. Conversely, horsepower $(\rho=0.45)$, diesel engines ( $\rho=0.11$ ), five-door options ( $\rho=0.16$ ), and all other special features are positively correlated with prices. While not listed in Table 1, another determinant for the price of a car is its color. We therefore also define a set of color indicators to control for their impact on prices, where the effects are measured relative to the color black. We find that prices are indeed somewhat responsive to different colors. To improve readability, however, we omit the coefficients for the color dummies in the regression tables that follow.

\footnotetext{
${ }^{11}$ The information on the month and year of first registration are stored in the variables fr_month $\in[1,12]$ and fr_year $\in[2000,2007]$, respectively. We combine these to define the variable totalage $\in[1,96]$ that captures the precise age of a car measured in months: totalage $\equiv 12 \cdot(2007-$ fr year $)+$ $\left(13-f r_{-}\right.$month). As a result, the youngest car in our sample (first-registration date of 12/2007) will be assigned a totalage value of 1 month.
} 
Figure 4. Distribution of car mileage

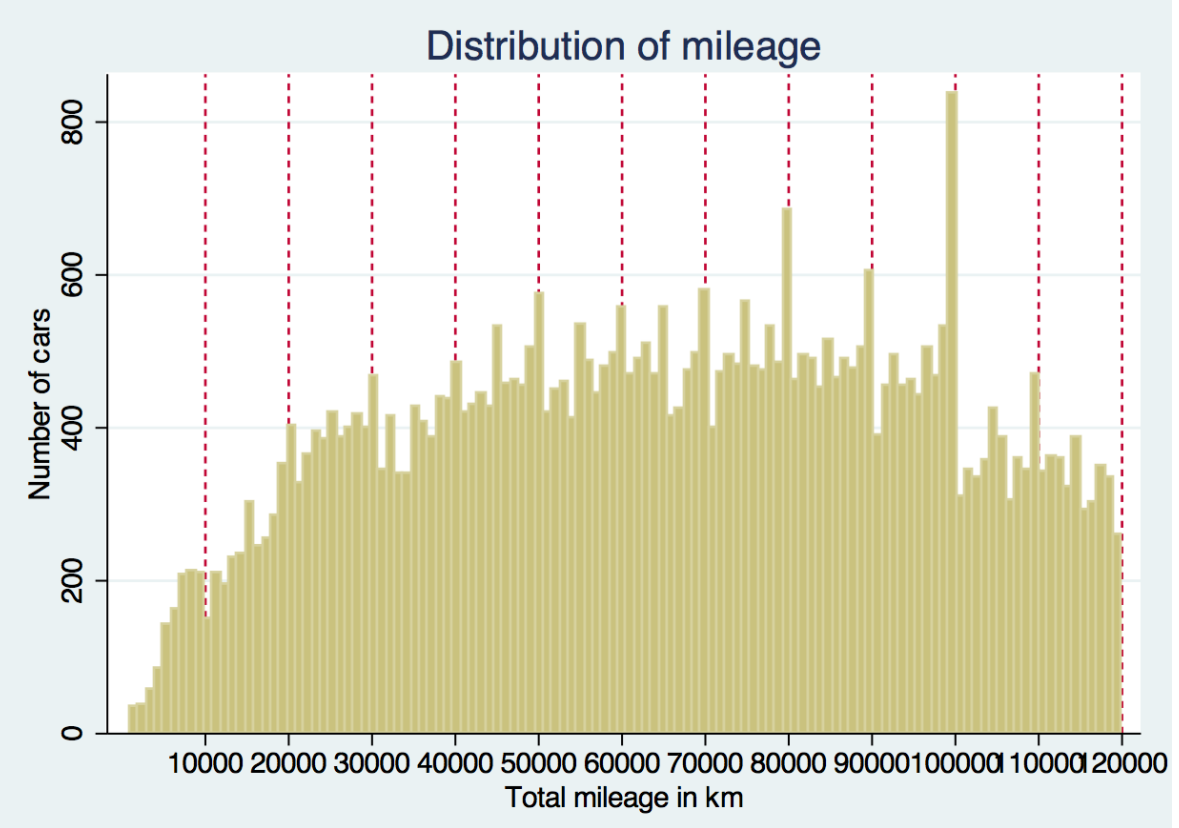

Notes: Plotted is the distribution of car mileage, measured in 1,000-km bins. Vertical lines indicate $10,000-\mathrm{km}$ thresholds.

Figure 5. Distribution of car age

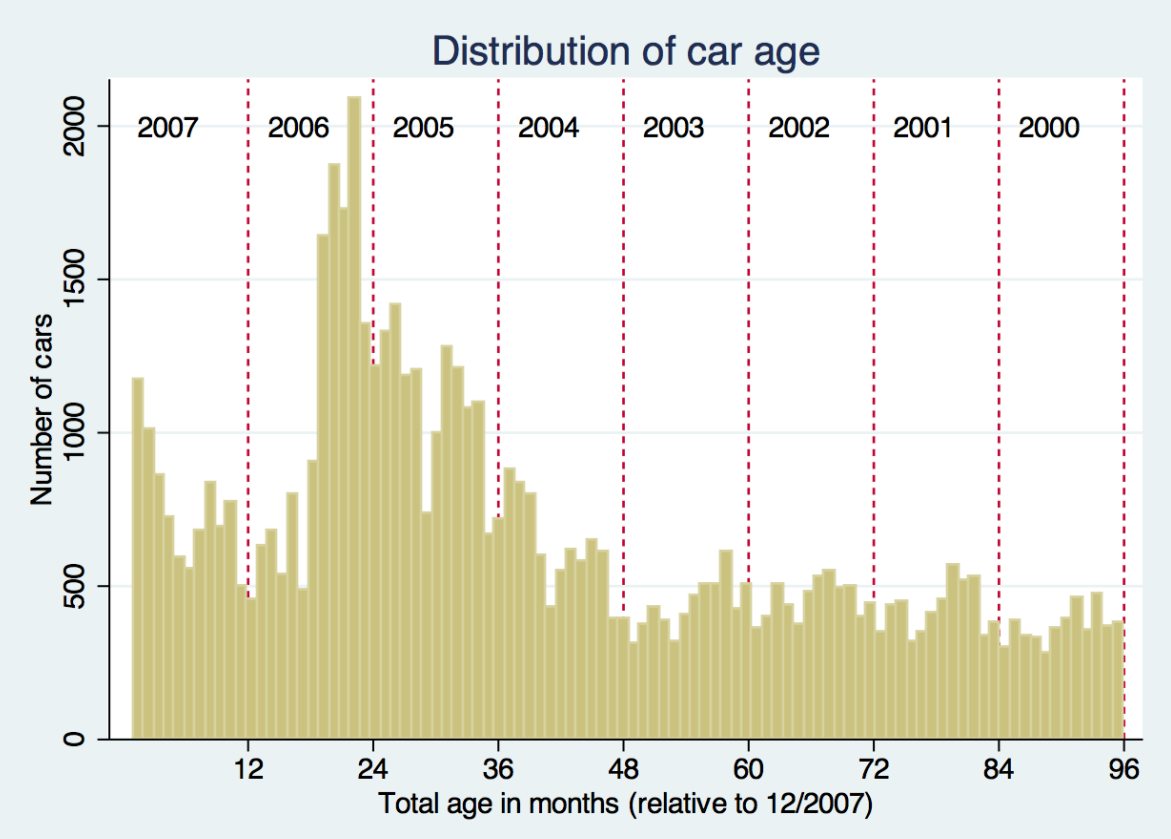

Notes: Plotted is the distribution of car age, measured in months (relative to the youngest car in the sample). Vertical lines indicate vintage thresholds.

Note that our two key explanatory variables - mileage and vintage of a car - are self-reported. While this is unlikely to be a concern for the latter because the date of first registration is officially mandated and easily verifiable, we suspect our odometer data to be more susceptible to measurement error. In fact, when plotting the raw mileage data (not depicted here for lack of space), we observe a discontinuous distribution, where much of the mass is on exact multiples of $1,000 \mathrm{~km}$, which indicates 
Figure 6. Distribution of car prices

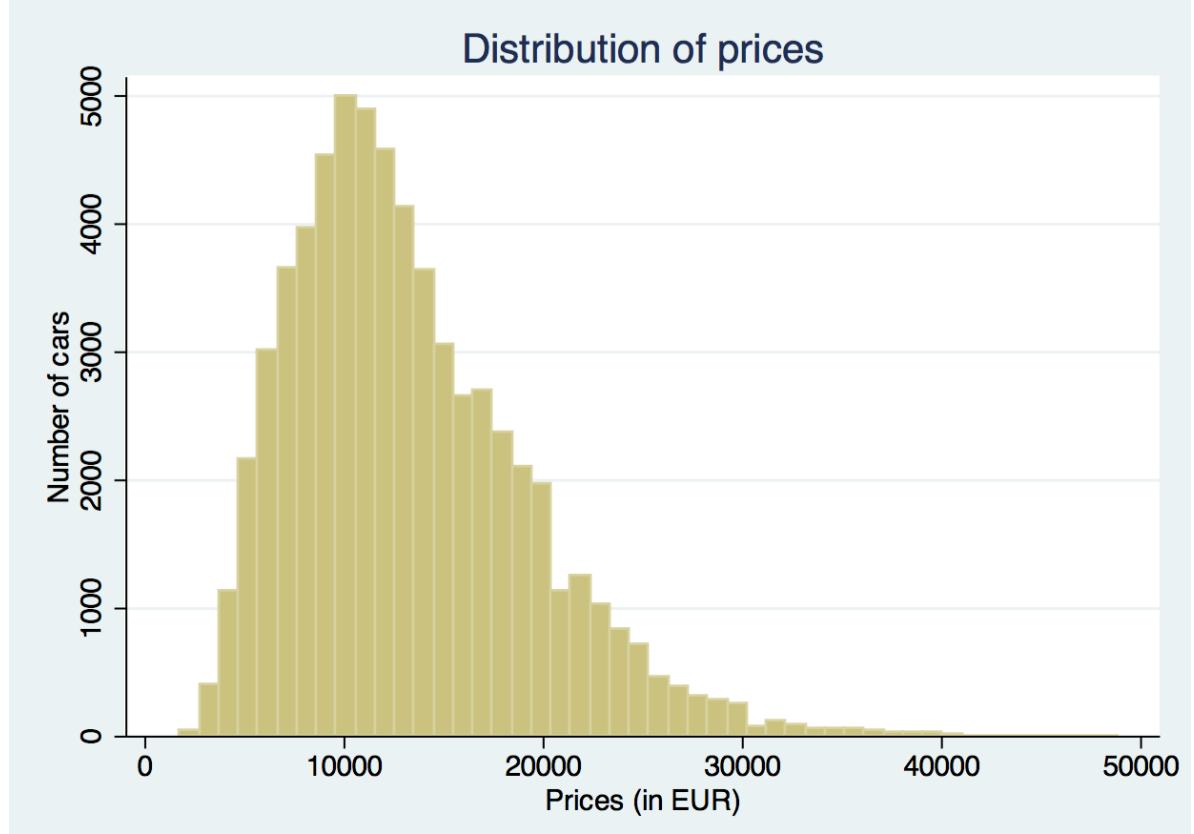

Notes: Plotted is the distribution of car prices, measured in EUR 1,000 bins.

considerable rounding. A similar picture emerges in Figure 4, where the distribution of car mileage is measured in 1,000-km bins: There is considerably more mass in the neighborhood to the left of 10,000-km thresholds (including the threshold itself) than to the right of the thresholds - a pattern that we discuss in Section 3.2. The distribution of car age is depicted in Figure 5. We find some fluctuations across registration months with a relative mass between roughly 18 and 40 months. Importantly, there are no systematic jumps around vintage thresholds but the data follows the seasonal pattern of first registrations that the Federal Office for Motor Vehicles records since 1970: There are generally few registrations in winter, then numbers pick up in spring, peak in summer, and decrease throughout the fall before reaching the low winter levels again. Finally, Figure 6 reveals that the distribution of our dependent variable - car prices - is somewhat right-skewed but approximately normally distributed.

\section{Empirical analysis}

\subsection{Vintage discontinuities}

\section{Graphical analysis}

We begin our empirical analysis by plotting the price data as a function of car age. In Figure 7 , each dot represents the average adjusted ${ }^{12}$ residual asking price (after controlling for a fifth-order age polynomial, mileage, horsepower, model updates, and

\footnotetext{
${ }^{12}$ To facilitate the readability of Figure 7 , we add the estimated age polynomial and a constant back into the residual.
} 
Figure 7. Average adjusted residual car prices by car age

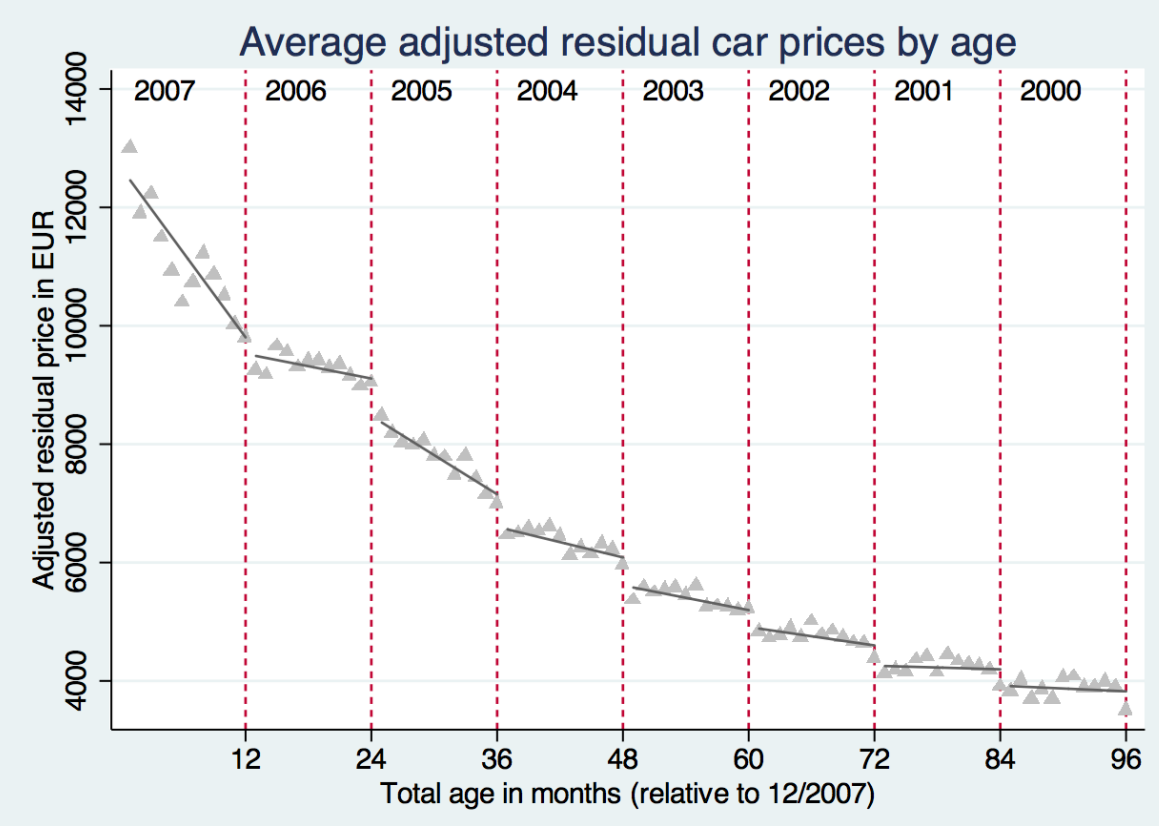

Notes: Plotted are average adjusted residual car prices (after controlling for car characteristics) as a function of car age measured on a monthly basis. Age is measured relative to the date of first registration $12 / 2007$. Vertical dashed lines indicate vintage (or registration year) thresholds. Solid lines represent linear fits within each vintage.

other car features) for all cars first registered in a given month of a given year. ${ }^{13}$ The vertical lines represent the vintage thresholds. As one would expect, prices decrease with age. While the decline in prices is continuous and approximately linear within each vintage, there are systematic and substantial discontinuities between vintages. This pattern is consistent with inattentive price-setting behavior where too much weight is given to the registration year of a car as opposed to the much more informative registration date.

\section{Regression analysis}

To corroborate the graphical analysis and to obtain numerical estimates for the observed price discontinuities, we continue with econometric analysis. Our identification strategy is based on a regression discontinuity (RD) design (see Lee and Lemieux (2010) for an overview). Particularly, to identify the discontinuities at vintage thresholds, we estimate the OLS regression

$$
p_{i}=\sum_{y=1}^{7} \beta_{y}^{v} D_{y i}^{v}+f\left(a_{i}\right) \boldsymbol{\gamma}^{v}+\mathbf{X}_{\mathbf{i}}^{\prime} \boldsymbol{\delta}^{v}+\epsilon_{i}^{v},
$$

where $p_{i}$ is the price of car $i$, and $\mathbf{X}_{\mathbf{i}}^{\prime}$ is a vector of observable car characteristics, $f(\cdot)$ is a polynomial function of car age, $a_{i}$, and captures the continuous relationship be-

\footnotetext{
${ }^{13}$ See Figure A.1 in Online Appendix A for the same analysis using raw price data.
} 
tween the age of a car and its price. ${ }^{14}$ We also include seven (one for each of the seven registration-year thresholds covered by our sample) dummy variables, $D_{y i}^{v}$ that indicate whether a car has crossed a given vintage threshold. The corresponding $\beta_{y}^{v}$ coefficients are the parameters of interest, as they measure the discontinuous difference in prices - conditional on precise car age $a_{i}$ - between cars that were registered in subsequent years. The intuition of this approach is that the coarse registration-year information should have no additional impact on car prices, once the much finer carage information is accounted for.

Table 2 presents estimation results for Regression 1 with varying sets of controls. ${ }^{15}$ Column (1) merely controls for a fifth-order age polynomial and the full set of threshold indicators and provides estimates of the price discontinuities before accounting for any heterogeneity in the car population. Given the important role of (thus far uncontrolled) model updates, these somewhat unsystematic results should be interpreted with caution. In Columns (2) through (5), we increase the number of control variables. Column (2) adds controls for the car features listed in Table 1, which substantially increases $\mathrm{R}^{2}$ and affects significance, size, and in some cases even the sign of the coefficients. In Column (3) we augment the control vector by information on model updates while Column (4) includes model fixed effects. Column (5) is the most encompassing specification as it simultaneously controls for all of the aforementioned characteristics. Once heterogeneity in car features is accounted for, five out of seven of the coefficients of interest are significantly negative, whereas the other two are indistinguishable from zero. These results closely mirror the graphical analysis above and provide strong evidence for systematic price discontinuities when passing vintage threshold, even after controlling for precise car age and a large number of additional car features.

The estimated discontinuities are also economically significant. For instance, the average price drop at vintage thresholds in the specification without car-model fixed effects (Column (3)) is EUR 418.79, whereas the average devaluation within vintages amounts to only EUR 79.80 per month. Assuming a linear relationship between car prices and age allows for a back-of-the-envelope approximation of an inattention parameter in the spirit of Lacetera et al. (2012): ${ }^{16}$ The average car in our sample loses EUR 1,296.59 per year in value, which implies an inattention parameter of $\frac{418.79}{1,296.59}=0.32$, suggesting that roughly $32 \%$ of the annual depreciation occurs in a

\footnotetext{
${ }^{14}$ In our main specification, we use a fifth-order polynomial to control for age. This specific functional form was chosen based on the Akaike Information-Criterion Test. Our results are robust to using lower-order and higher-order polynomials, as discussed in Section 4.

${ }^{15}$ The drop in sample size from Column (1) to Column (2) is due to variation in the availability of information on certain car features, especially horsepower, engine displacement, transmission kind, and fuel kind.

${ }^{16}$ While this specific functional form is unlikely to be the best fit for our data, it is a simplification commonly used in the literature, see, e.g., DellaVigna (2009) or Lacetera et al. (2012).
} 
Table 2. The impact of vintage thresholds on car prices

Dependent variable: Car prices

Regression coefficients

(Robust standard errors in brackets)

\begin{tabular}{|c|c|c|c|c|c|c|c|}
\hline Explanatory variables & (1) & (2) & (3) & (4) & (5) & (6) & (7) \\
\hline \multicolumn{8}{|l|}{ Indicator for... } \\
\hline \multirow[t]{2}{*}{...FR before 2007} & $430.7^{*}$ & 54.7 & -203.0 & -14.4 & $-221.4^{*}$ & $-219.0^{*}$ & $-848.8^{*}$ \\
\hline & (176.9) & (108.4) & (108.0) & (92.1) & (91.8) & (92.4) & (394.5) \\
\hline \multirow[t]{2}{*}{...FR before 2006} & $-501.8 * * *$ & $-613.7^{* * *}$ & $-858.4^{* * *}$ & $-580.5 * * *$ & $-780.3 * * *$ & $-796.1 * * *$ & $-570.5^{*}$ \\
\hline & (116.4) & $(66.0)$ & $(67.5)$ & (55.4) & $(56.6)$ & (56.8) & $(281.2)$ \\
\hline \multirow[t]{2}{*}{...FR before 2005} & $-1228.1 * * *$ & $-581.3 * * *$ & $-698.6 * * *$ & $-516.0 * * *$ & $-609.2^{* * * *}$ & $-530.4 * * *$ & $-744.0 * * *$ \\
\hline & $(96.0)$ & (63.5) & (63.6) & $(54.6)$ & $(54.9)$ & $(59.5)$ & (156.6) \\
\hline \multirow[t]{2}{*}{...FR before 2004} & $576.9 * * *$ & -51.0 & -23.7 & -30.7 & -3.7 & 87.0 & $-551.6 * * *$ \\
\hline & (119.5) & (87.4) & (87.1) & $(79.2)$ & (77.7) & $(84.0)$ & (167.8) \\
\hline \multirow[t]{2}{*}{...FR before 2003} & -42.0 & -61.6 & -129.6 & 105.6 & 44.3 & 124.7 & $-339.6 * *$ \\
\hline & (100.5) & $(77.2)$ & $(76.8)$ & (69.4) & (68.9) & $(81.0)$ & (128.8) \\
\hline \multirow[t]{2}{*}{...FR before 2002} & $-895.0 * * *$ & $-394.3 * * *$ & $-568.4 * * *$ & $-293.2^{* * *}$ & $-437.9 * * *$ & $-412.9 * * *$ & $-383.6 * *$ \\
\hline & $(107.2)$ & $(88.7)$ & (88.6) & $(82.7)$ & (83.5) & $(101.5)$ & $(142.2)$ \\
\hline \multirow[t]{2}{*}{...FR before 2001} & $-959.6 * * *$ & $-414.2 * * *$ & $-449.7 * * *$ & $-316.7 * * *$ & $-345.1 * * *$ & $-387.5 * * *$ & -108.6 \\
\hline & (94.1) & (93.7) & (93.5) & $(90.9)$ & (91.7) & (112.3) & $(146.5)$ \\
\hline
\end{tabular}

\section{Controls}

- Car-age polynomial

- Car features

$\mathrm{X}$

$\mathrm{X}$
$\mathrm{X}$

$\mathrm{X}$

$\mathrm{X}$

$X$
$X$

$\mathrm{X}$
$\mathrm{X}$
$\mathrm{X}$

$\begin{array}{ll}X & X \\ X & X \\ X & X \\ X & X\end{array}$

- Car-model fixed effects

- Seller type

$\mathrm{X}$

$\mathrm{X}$

$\mathrm{X}$

$\mathrm{X}$

$\mathrm{X}$

Sample selection

\begin{tabular}{lccccccc} 
- Commercial sellers & $\mathrm{X}$ & $\mathrm{X}$ & $\mathrm{X}$ & $\mathrm{X}$ & $\mathrm{X}$ & $\mathrm{X}$ & \\
- Private sellers & $\mathrm{X}$ & $\mathrm{X}$ & $\mathrm{X}$ & $\mathrm{X}$ & $\mathrm{X}$ & & $\mathrm{X}$ \\
\hline $\mathrm{R}^{2}$ & 0.4543 & 0.8148 & 0.8161 & 0.8576 & 0.8584 & 0.8630 & 0.8376 \\
$\mathrm{~N}$ & 63,340 & 50,872 & 50,872 & 50,872 & 50,872 & 43,020 & 7,852 \\
\hline
\end{tabular}

Notes: Results are for the main empirical specification (see Section 3.1). Depicted are estimates for $\beta_{y}^{v}$. FR stands for "first registered". Car age is controlled for by a fifth-order polynomial (chosen based on the Akaike Information Criterion Test). Car features include all car characteristics listed in Table 1. Seller type distinguishes between commercial and private sellers. Robust standard errors are stated in brackets. $*$, **, and *** indicate statistical significance at the $5 \%$, the $1 \%$, and the $0.1 \%$ level, respectively.

threshold month - a value that falls well within the range of inattention parameters documented in the literature (see DellaVigna, 2009). ${ }^{17}$

We continue by studying the heterogeneity of results with respect to the identity of the vendor and stratify our sample by seller type. Column (6) re-estimates the speci-

\footnotetext{
${ }^{17}$ For comparison, the specification with car-model fixed effects (Column (5)) yields a slightly smaller inattention parameter of $\frac{336.20}{1,320.95}=0.25$.
} 
fication from Column (5) in a sample of commercial sellers. Given that such institutional vendors make up almost $90 \%$ of our sample, it is hardly surprising that results closely mirror those from the main analysis. Interestingly, results become even more consistent in a sample of private sellers (Column (7)). Not only do we find negative discontinuities at all seven thresholds, but the average price drop is also significantly larger than for professional sellers (EUR 506.67 vs. EUR 304.88). This provides suggestive evidence that less experienced market participants may be more susceptible to underestimating the importance of accounting for the exact registration date when evaluating their car and setting the price.

A threat for identification in research-discontinuity settings is manipulative sorting around the thresholds, since asymmetric supply may potentially drive the observed price drops. Recall that we should not expect any anomalous bunching in the vintage dimension because the date of first registration is an inherent feature of a used car that cannot be changed by expediting or delaying its sale. Hence, it is impossible to strategically alter a car's relative position to the vintage thresholds. In fact, Figure 5 documents that there are no systematic differences in the supply of December and January cars but that the distribution of used-car offers follows the same seasonal pattern as that for new cars (see Section 2.3).

While we deem it plausible to interpret the uncovered discontinuities as due to inattention, our results could potentially be driven by other factors as well. For instance, unobservable heterogeneity around registration-year thresholds could produce similar patterns in the data. To use an example by an anonymous referee, cars that were first registered in December, say as a Christmas gift, may have been treated systematically different than cars that were first registered in January. While it will always be possible to construct such examples of alternative explanations as long as there is unobservable information - which is invariably the case in any empirical work with observational data - there are several features of the German market for new cars that work in our favor: In most cases, buyers of factory-new cars are unable to choose precisely when their car is delivered and, consequently, first registered. With waiting periods ranging from several weeks to even months (depending on the specific car model), the actual purchase of "December cars" and "January cars" (according to their first registration) will likely have occurred in the preceding fall. For the purpose of our study, this waiting time is an advantage, as it adds randomness to the date of first registration. As a result, the initial buyer lacks full control over the timing of events, which moves us closer to an ideal experiment where registration dates would be randomly allocated. Moreover, uncontrolled climatic differences are unlikely to be at work either because German Decembers and Januaries are equally prone to snow and the use of corroding road salt. There are also no general market 
patterns that would suggest differences in prices (including discounts) or the amount of cars sold between December and January when the cars were new. ${ }^{18}$

In a similar vein, another anonymous referee suggested that a discussion of car warranties - which could potentially be behind the vintage discontinuities - was warranted. In Germany, there is a legally mandated two-year warranty for any product upon purchase. ${ }^{19}$ In addition, car manufacturers often provide additional voluntary warranties that are defined for a certain time period (usually two years) after first registration. Since our data is from the summer of 2009, the vast majority of warranties in our sample will already have expired, and even the ones that are still effective are not on the brink of systematically elapsing for December cars. For these reasons, it is highly unlikely that product warranties can explain the observed price drops at vintage thresholds.

While our case against the confounding influence of unobservable heterogeneity relies on verbal arguments alone, we are able to methodologically address the issue of observable heterogeneity around vintage thresholds. In Appendix B, we show that there are no systematic changes in observable car characteristics (other than price) at vintage thresholds, which suggests that December cars and January cars are indeed close substitutes and not drawn from inherently different populations.

\subsection{Mileage discontinuities}

We now turn to another car feature that could potentially be associated with price discontinuities: the odometer reading as stated in the sales offer. Recall that our carmileage data is likely subject to misreporting, which may explain that our results in this dimension are less robust than in the vintage dimension. Despite these concerns of measurement error, we are able to replicate the main findings by Lacetera et al. (2012).

\section{Graphical analysis}

We begin by plotting the price data as a function of car mileage. In Figure 8, each dot shows the average adjusted ${ }^{20}$ residual price (after controlling for a second-order mileage polynomial, car age, horsepower, model updates, horsepower, model up-

\footnotetext{
${ }^{18}$ For details, see the registration statistics by the Federal Office for Motor Vehicles and the monthly discount index ("Rabattindex") published by the Center for Automotive Research (CAR) at the University of Duisburg-Essen: https://www.uni-due.de/ hk0378/Rabatte_Index/CAR-Rabatt-Index-Dez12. pdf.

${ }^{19}$ This type of warranty, known as "Gewährleistung", also applies to the sale of used cars. However, non-commercial transactions are exempt from this regulation - a fact that is in line with our data: Controlling for car characteristics, cars offered by private sellers, not liable for Gewährleistung, are roughly $10 \%$ cheaper than those offered by professional dealerships.

${ }^{20}$ Again, we adjust residuals by adding the estimated mileage polynomial and a constant.
} 
Figure 8. Average adjusted residual car prices by car mileage

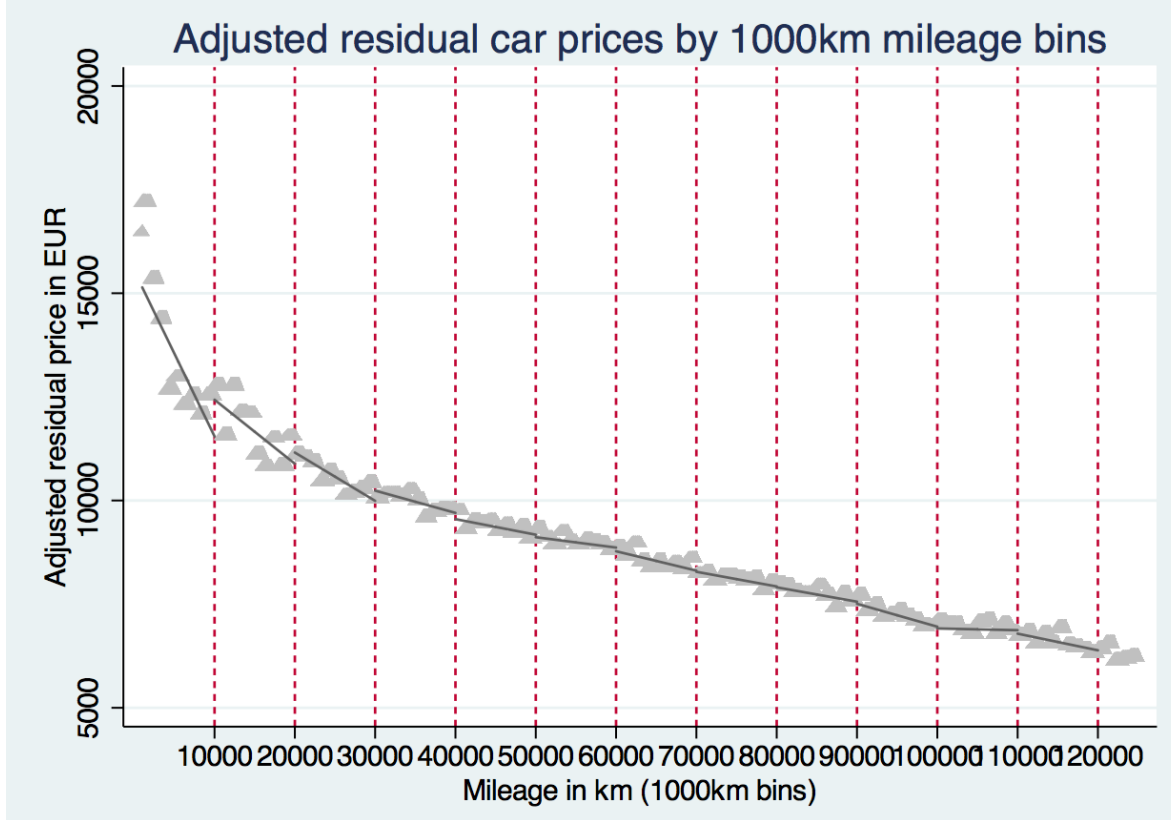

Notes: Plotted are average adjusted residual car prices (after controlling for car characteristics) as a function of car mileage measured in 1,000-km bins. Vertical dashed lines indicate 10,000-km mileage thresholds. Solid lines represent linear fits between thresholds.

dates, and other car features) for all cars that lie in the same 1,000-km odometer bin. ${ }^{21}$ The vertical lines represent $10,000-\mathrm{km}$ thresholds. Unsurprisingly, prices decrease with mileage. Within each 10,000-km bin, prices decline continously but there are systematic (albeit small) drops at the 10,000-km marks. ${ }^{22}$ With no apparent explanation for the importance of 10,000-km thresholds, this result is in line with the interpretation by Lacetera et al. (2012) that heuristic decision making plays a role in the mileage dimension as well.

\section{Regression analysis}

The regression approach follows the same logic as that for the vintage thresholds. To identify the 10,000-km mileage discontinuities, we implement an RD design where we estimate the following regression with OLS:

$$
p_{i}=\sum_{k=1}^{10} \beta_{k}^{m} D_{k i}^{m}+g\left(o_{i}\right) \boldsymbol{\gamma}^{m}+\mathbf{X}_{\mathbf{i}}^{\prime} \boldsymbol{\delta}^{m}+\epsilon_{i}^{m},
$$

The dependent variable is the car price and controls for car characteristics are collected in $\mathbf{X}_{\mathrm{i}}^{\prime}$. The continuous relationship between price and odomoter readings, $o_{i}$,

\footnotetext{
${ }^{21}$ See Figure A.2 in Online Appendix A for the same analysis using raw price data.

${ }^{22}$ Note that the trend lines, while helpful to visualize the downward price trend within and across bins, impair the visibility of the discontinuities. To see the latter, focus on the triangles right before and after each of the 10,000-km thresholds.
} 
is captured with the polynomial function $g(\cdot) .{ }^{23}$ To measure the impact of crossing a given $10,000-\mathrm{km}$ threshold, we include ten dummy variables, $D_{k i}^{m}$. The corresponding $\beta^{m}$ coefficients are the parameters of interest, as they measure the discontinuous difference in prices - conditional on the exact (stated) odometer reading $o_{i}$ - when a car crosses a 10,000-km mark.

Even though the graphical evidence appears less striking than was the case for the vintage discontinuities, the corresponding regression results in Table 3 are reassuring. ${ }^{24}$ As before, Column (1) controls only for the mileage polynomial and the full set of indicator variables. As we move trough Columns (2) to (5), control for car heterogeneity becomes more encompassing. When accounting for all observable characteristics in Column (5), each threshold coefficient is significantly negative and sizable, suggesting economically meaningful price discontinuities at 10,000-km marks. The average price drop at 10,000-km thresholds in Column (3) amounts to EUR 367.33 compared to an average price decrease between thresholds of EUR 63.26 per $1,000 \mathrm{~km}$. The corresponding inattention parameter in the spirit of Lacetera et al. (2012) would be approximated by $\frac{367.33}{936.65}=0.39$, implying that about $39 \%$ of the depreciation per $10,000 \mathrm{~km}$ occurs at the moment a car passes a threshold. ${ }^{25}$

When dividing the sample with respect to seller type in Columns (6) and (7), results are markedly different from those in the vintage dimension, where the discontinuities were more pronounced and consistent for private sellers. In the mileage dimension, the average price drop at $10,000-\mathrm{km}$ thresholds is roughly the same for private and commercial sellers (EUR 350.17 versus EUR 362.37). Moreover, the estimates from the private-seller sample greatly suffer from increased imprecision, resulting in a less consistent pattern for this type of vendor. It is possible that this blurred evidence is attributable to the measurement concerns of our odometer data, assuming that commercial (and legally liable) vendors report car mileage with more accuracy than private sellers. On this account, it is not surprising that our results mirror those by Lacetera et al. (2012) - who rely on verifiable mileage data from commercial auctions - more closely in the subsample that is institutionally more similar to theirs.

In contrast to the distribution of car age - and in line with expectations - Figure 4 provides evidence for manipulative sorting in the mileage dimension, as there is considerable bunching of offers right before a car passes 10,000-km thresholds. This may either be misreporting or the result of a strategic decision to sell a car before the

\footnotetext{
${ }^{23}$ In our main specification we use a second-order polynomial to control for mileage. Again, this specific functional form was chosen based on the Akaike Information-Criterion test. The robustness with respect to other polynomials is discussed in Section 4.

${ }^{24}$ Again, the drop in sample size from Column (1) to (2) is due to variation in the availability of information on certain car features.

${ }^{25}$ Results from the specification with car-model fixed effects (Column (5)) suggest a nearly identical inattention parameter of $\frac{375.80}{960.44}=0.39$.
} 
Table 3. The impact of mileage thresholds on car prices

Dependent variable: Car prices

Regression coefficients

(Robust standard errors in brackets)

\begin{tabular}{|c|c|c|c|c|c|c|c|}
\hline Explanatory variables & (1) & (2) & (3) & (4) & (5) & (6) & (7) \\
\hline \multicolumn{8}{|l|}{ Indicator for... } \\
\hline \multirow[t]{2}{*}{...more than $10 \mathrm{~K} \mathrm{~km}$} & $-1,582.4^{* * * ;}$ & $*-994.5 * * *$ & $-1,022.9 * * ;$ & $-888.7 * * *$ & $-905.9 * * *$ & $-868.5 * * *$ & -1093.1 \\
\hline & $(249.1)$ & $(174.2)$ & $(173.4)$ & $(160.8)$ & $(160.5)$ & $(162.5)$ & $(823.6)$ \\
\hline \multirow[t]{2}{*}{...more than $20 \mathrm{~K} \mathrm{~km}$} & $-1075.1 * * *$ & $-789.7 * * *$ & $-779.4 * * *$ & $-758.0 * * *$ & $-749.2 * * *$ & $-775.7 * * *$ & -71.3 \\
\hline & (164.7) & (109.1) & (108.3) & $(96.2)$ & (95.7) & $(100.0)$ & (301.7) \\
\hline \multirow[t]{2}{*}{...more than $30 \mathrm{~K} \mathrm{~km}$} & $-420.1 * *$ & $-359.1 * * *$ & $-368.6 * * *$ & $-362.3 * * *$ & $-368.8 * * *$ & $-416.6 * * *$ & 101.3 \\
\hline & $(133.8)$ & $(83.1)$ & $(82.7)$ & $(71.6)$ & (71.4) & $(75.0)$ & $(251.3)$ \\
\hline \multirow[t]{2}{*}{...more than $40 \mathrm{~K} \mathrm{~km}$} & $-576.3 * * *$ & $-372.6 * * *$ & $-378.8 * * *$ & $-424.1 * * *$ & $-428.4 * * *$ & $-382.2 * * *$ & $-782.6 * * *$ \\
\hline & (120.9) & $(69.8)$ & (69.6) & $(59.2)$ & $(59.1)$ & $(62.2)$ & $(215.2)$ \\
\hline \multirow[t]{2}{*}{...more than $50 \mathrm{~K} \mathrm{~km}$} & $-442.4 * * *$ & $-146.1^{*}$ & $-141.0 *$ & $-168.5^{* * *}$ & $-163.9 * * *$ & -91.2 & $-568.3 * *$ \\
\hline & (113.7) & $(60.5)$ & $(60.4)$ & $(51.6)$ & $(51.6)$ & (54.6) & $(180.4)$ \\
\hline \multirow{2}{*}{...more than $60 \mathrm{~K} \mathrm{~km}$} & -101.1 & $-210.7 * * *$ & $-212.3 * * *$ & $-241.2^{* * *}$ & $-242.9 * * *$ & $-243.9 * * *$ & -162.9 \\
\hline & $(111.3)$ & (57.5) & (57.6) & (48.9) & (48.9) & (52.6) & (151.2) \\
\hline \multirow[t]{2}{*}{...more than $70 \mathrm{~K} \mathrm{~km}$} & $-586.8 * * *$ & $-221.3 * * *$ & $-220.0 * * *$ & $-235.9 * * *$ & $-234.6 * * *$ & $-207.7 * * *$ & $-272.4 *$ \\
\hline & $(106.2)$ & $(55.2)$ & (55.3) & $(46.9)$ & $(46.8)$ & (50.7) & $(138.5)$ \\
\hline \multirow[t]{2}{*}{...more than $80 \mathrm{~K} \mathrm{~km}$} & -108.8 & $-143.9 * *$ & $-143.8 * *$ & $-213.3 * * *$ & $-212.9 * * *$ & $-201.5 * * *$ & $-247.9 *$ \\
\hline & $(103.0)$ & (52.9) & (52.9) & $(45.2)$ & $(45.2)$ & (49.6) & (119.9) \\
\hline \multirow[t]{2}{*}{...more than $90 \mathrm{~K} \mathrm{~km}$} & $-414.1 * * *$ & $-289.5 * * *$ & $-284.9 * * *$ & $-284.9 * * *$ & $-281.8 * * *$ & $-269.1 * * *$ & $-250.8^{*}$ \\
\hline & $(100.4)$ & (50.7) & (50.7) & (43.8) & (43.8) & (48.6) & (104.6) \\
\hline \multirow[t]{2}{*}{...more than $100 \mathrm{~K} \mathrm{~km}$} & -71.2 & $-125.3^{*}$ & $-121.6^{*}$ & $-172.7^{* * *}$ & $-169.6 * * *$ & $-167.3 * * *$ & -153.7 \\
\hline & $(103.5)$ & $(53.1)$ & $(53.1)$ & (46.4) & $(46.4)$ & $(50.8)$ & (114.7) \\
\hline \multicolumn{8}{|l|}{ Controls } \\
\hline - Car-mileage polynomial & $\mathrm{X}$ & $\mathrm{X}$ & $\mathrm{X}$ & $\mathrm{X}$ & $\mathrm{X}$ & $\mathrm{X}$ & $\mathrm{X}$ \\
\hline - Car features & & $\mathrm{X}$ & $\mathrm{X}$ & $\mathrm{X}$ & $\mathrm{X}$ & $\mathrm{X}$ & $\mathrm{X}$ \\
\hline - Car-model updates & & & $\mathrm{X}$ & & $\mathrm{X}$ & $\mathrm{X}$ & $\mathrm{X}$ \\
\hline - Car-model fixed effects & & & & $\mathrm{X}$ & $\mathrm{X}$ & $\mathrm{X}$ & $\mathrm{X}$ \\
\hline - Seller type & $\mathrm{X}$ & $\mathrm{X}$ & $\mathrm{X}$ & $\mathrm{X}$ & $\mathrm{X}$ & & \\
\hline \multicolumn{8}{|l|}{ Sample selection } \\
\hline - Commercial sellers & $\mathrm{X}$ & $\mathrm{X}$ & $\mathrm{X}$ & $\mathrm{X}$ & $\mathrm{X}$ & $\mathrm{X}$ & \\
\hline - Private sellers & $\mathrm{X}$ & $\mathrm{X}$ & $\mathrm{X}$ & $\mathrm{X}$ & $\mathrm{X}$ & & $\mathrm{X}$ \\
\hline$R^{2}$ & 0.2634 & 0.8141 & 0.8148 & 0.8572 & 0.8575 & 0.8595 & 0.8411 \\
\hline $\mathrm{N}$ & 63,340 & 50,872 & 50,872 & 50,872 & 50,872 & 43,020 & 7,852 \\
\hline
\end{tabular}

Notes: Results are for the main empirical specification (see Section 3.2). Depicted are estimates for $\beta_{k}^{m}$. Car mileage is controlled for by a second-order polynomial (chosen based on the Akaike Information Criterion Test). Car features include all car characteristics listed in Table 1. Seller type distinguishes between commercial and private sellers. Robust standard errors are stated in brackets. *, **, and $* * *$ indicate statistical significance at the $5 \%$, the $1 \%$, and the $0.1 \%$ level, respectively. 
odometer passes a salient (and value-destroying) threshold. In any case, it suggests that sellers at least believe prospective buyers to be inattentive when evaluating car offers. Importantly, this pattern does not provide an alternative explanation for the observed price drops because excess supply of cars with odomoter values below the thresholds should depress, rather than inflate, prices for cars in this crowded market segment.

Unobserved heterogeneity in the car population around 10,000-km mileage thresholds is unlikely to be a concern in the mileage dimension because - in contrast to the vintage dimension - the relative position with respect to a threshold is neither an innate car feature, nor subject to the way a car was used. In addition, none of the manufacturers in our sample offers mileage-based warranties, eliminating this potential source of confounding as well. Of course, one could argue that vendors who strategically sell their car before a threshold is passed (or alternatively: who underreport odometer values to boost the car value) may also systematically treat their car differently. However, we believe such considerations to be largely speculative and even the direction of any potential bias would be ex-ante unclear. This is why we limit our discussion in Appendix $\mathrm{C}$ to documenting the absence of observable heterogeneity around 10,000-km thresholds.

\section{Robustness analysis}

\section{Vintage discontinuities}

In Online Appendix B, we present an extensive set of robustness checks for our analysis in the vintage dimension. We start by examining empirical pitfalls typical for research-discontinuity settings. In Figures B.1-B.4 we provide graphical evidence that our results are not driven by changing market compositions around the thresholds. We also perform placebo tests by creating indicators for artificial year thresholds. Results in Table B.1 document that these placebo thresholds do not exhibit systematic discontinuities.

We continue by gauging the robustness of results to changes in the main empirical specification. Since prices have a long right tail (recall Figure 6), it seems appropriate to log-linearize Regression 1. As results in Table B.2 reveal, this modification produces even more consistent results. In our main specification, we classify a car as having undergone a model update if its first registration occurred more than three months after factories switched production. Table B.3 documents that results are robust to varying definitions of model-update dummies. Finally, results in Table B.4 show that our conclusions remain intact when using lower-order or higher-order polynomials than those endorsed by the Akaike Information-Criterion Test. 


\section{Mileage discontinuities}

Online Appendix C repeats the analysis from Online Appendix B in the mileage dimension. Figures C.1-C.4 provide evidence that cars to the left and to the right of mileage thresholds are comparable in their observable charcteristics. Moreover, we perform a placebo test by converting odometer readings from kilometers to US miles. Given that Germany exclusively uses the metric system, US-mile thresholds should be irrelevant even if heuristics play a role in decision making. Indeed, results in Table C. 1 show that all but the first 10,000-mile placebo thresholds are associated with insignificant coefficients.

Empirical robustness of results with respect to changes in the main specification is less convincing for the mileage dimension than it was for the vintage dimension. For instance, log-linearization is not innocuous but even reverses results for some of the 10,000-km thresholds (see Table C.2). ${ }^{26}$ While Table C.3 documents robustness to varying definitions of model-update dummies, results are somewhat sensitive to using mileage polynomials of orders higher than three, whereas lower-order polynomials work fine (see Table C.4). However, note that specifications that accommodate higher-order polynomials appear to suffer from multicollinearity and our statistical software fails to provide the F-Test statistic, which suggests that results are in line with expectations, as long as the econometric model is not misspecified.

\section{A horserace}

As a final robustness exercise, Online Appendix D implements a horserace specification by jointly controlling for mileage and vintage thresholds. Results in Table D.1 show that both discontinuities exist independently of one another. Not only do effects in either dimension survive, but especially the vintage discontinuities are even slightly more pronounced.

\section{Discussion and conclusion}

We study the price-setting behavior in a competitive market for used cars and provide empirical evidence for coarse information processing. Based on detailed field data from one of Europe's largest online marketplaces for automotive vehicles, we document systematic and sizable price discontinuities at salient car-age and mileage thresholds. The price difference between two otherwise identical cars across registration years (where one was first registered in January and the other in December of the previous year) is up to five times larger than that between two cars first regis-

\footnotetext{
${ }^{26}$ However, given the concerns of measurement error in our mileage data, we are certainly not inclined to call the findings by Lacetera et al. (2012) - who document systematic and sizable discontinuities with more reliable data in the mileage dimension - into question.
} 
tered in any two subsequent months within a registration year. A similar pattern can be observed in the mileage dimension at $10,000-\mathrm{km}$ odometer marks, which is in line with earlier findings by Lacetera et al. (2012).

Given the high-stake nature of a car sale, these price discontinuities are quite intriguing and raise the natural question about the driving force behind this behavioral pattern. We argue that it can be explained by a simple model of limited attention in the spirit of DellaVigna (2009), where the overall value of a car, $V$, is the sum of a salient component, $s$, and an opaque component, $o: V=s+o$. In the context of the vintage (mileage) dimension, $s$ would be determined by the registration year (the left-most digit in the odometer reading), whereas the value $o$ would be influenced by the precise registration month (the digits to the right of the first odometer digit). ${ }^{27}$ Limited attention is modeled by the assumption that market participants perceive the car value to be $\hat{V}=s+(1-\theta) o$, where $\theta$ measures the degree of inattention. Note that the opaque information need not necessarily be hidden or difficult to access. As is the case with the exact date of registration and mileage of a car, $o$ can be clearly visible at no cost, but individuals - for some reason - fail to fully process it at rate $\theta$. The key question in this framework is what this reason might be.

On the one hand, inattention may be driven by bounded rationality. According to this notion, individuals tend to follow heuristics, which imply optimization under the constraint that processing information, while beneficial, is psychologically costly. An example for such a heuristic is left-digit bias, which Lacetera et al. (2012) argue to be the psychological mechanism behind price discontinuities in the mileage domain. Note that while left-digit bias - if applied narrowly - cannot explain that the price difference between two cars registered in December 2004 versus January 2005 is larger than the one between January 2005 and February 2005, we do not interpret our results in the vintage domain to be at odds with their interpretation. Instead, we believe that a more general notion of information-prominence bias (where left-digit bias can be thought of as a special case) can accommodate both our findings and those by Lacetera et al. (2012), and would be applicable to a wide set of domains where underlying continuous characteristics are mapped into discrete categories (such as classifications of French wine, star-based reviews of hotels, or ratings of financial assets). Future research will likely shed additional light on the generality of inattention-induced discontinuities in other economic contexts. ${ }^{28}$

On the other hand, it is possible that inattention has a more rational footing. DellaVigna (2009) (p.349) emphasizes that "in general, models of limited attention can be rephrased as rational models with information costs in which less salient information has higher costs of acquisition." While this alternative explanation seems to be inapplicable to our context (where the exact information on mileage and reg-

\footnotetext{
${ }^{27}$ For simplicity, we abstract from the impact of other car features on $V$.

${ }^{28}$ In fact, in a recent study, Luca (2016) finds evidence for coarse information processing by consumers when evaluating restaurant ratings from yelp.com.
} 
istration date is readily visible at no cost) at first glance, we argue that at least part of the observed discontinuities may in fact be driven by implicit search costs. Our intuition is that inattentive individuals will evaluate a given vehicle relative to the average car from an easily accessible "comparison sample" (here: the same vintage or mileage bin), while the more relevant comparison group consists of cars of similar age or mileage, irrespective of the vintage or mileage bin they belong to. For instance, a car first registered in December of 2006 should be contrasted with cars of comparable age, say within a six-months window (cars first registered between September of 2006 and March of 2007). However, mobile.de's search filter does not allow to adjust inquiries for the precise month of first registration. In order to obtain the desired information, one would have to screen a substantially higher number of offers, namely the entire universe of cars registered in 2006 and 2007. These potential search costs discourage the comparison of offers across vintages and increase the likelihood that individuals are simply unaware of the systematic price differentials. ${ }^{29}$

Discriminating between the relative roles of behavioral bias and traditional search frictions in explaining price discontinuities is an important challenge for future research (see Schneider, 2016 and Malmendier, 2016). On this account, Englmaier et al. (2016) study an online market for virtual goods that exhibit similar price discontinuities in the age domain: the soccer-manager game hattrick.org. Their paper exploits an exogenous change in the website's search interface that resulted in the elimination of search cost for precise product age and finds that while price drops at thresholds were significantly reduced, substantial discontinuities remained.

The presence, persistence, and relevance of coarse information processing documented by this and other papers in various consumer-choice contexts has important managerial implications. Clearly, the scope of applications is not limited to the automotive sector but relates to any good for which consumers base their decisions on salient parameters. Examples are, as mentioned above, financial products (ratings), but also real estate (living space), computers (processor speed), or food (sugar content). For instance, in the area of product design our results imply that endogenous product features should strategically stay below (sugar content of a beverage) or above (living space of a new construction) salient thresholds. In case of exogenous product features, attention needs to be devoted to making the "right" features salient.

Another relevant question aims at the economic and welfare implications of the price discontinuities in the investigated used-car market. Given that a substantial amount of cars will be overpriced relative to their objective characteristics, there will be redistributive effects to the detriment of inattentive buyers. At the same time, it is possible that overpricing leads to too little trade and a real loss in surplus, as overly expensive vehicles may be shunned by rational buyers, causing a welfare loss

\footnotetext{
${ }^{29}$ Since the website's filter mechanism only allows to narrow down search results along 10,000-km odometer brackets, a comparable argument applies to the mileage dimension as well.
} 
among market participants who try (and fail) to sell their prohibitively priced January cars. Similarly, owners of December cars may be discouraged to even put their car up for sale at such low prices, reducing trade from the supply side as well. While these inefficiencies make the case for the elimination of price discontinuities from a social planner's point of view, it is not clear that marketplace providers would favor such action, too. Although market efficiency would likely be increased, a majority of sellers might prefer the market segmentation because their products will appear more differentiated than they really are, thereby weakening competition. Since in most two-sided markets of this kind, positive prices are only paid by sellers, the platform providers may have an incentive to cater to their preferences and hence prefer to keep the discontinuities in place. Analyzing these implications for platform pricing and more general industrial-organizational aspects are promising topics for future research.

\section{References}

Brown, J., Hossain, T. and Morgan, J. (2010). Shrouded attributes and information suppression: Evidence from the field. Quarterly Journal of Economics, 125(2), 859-876. 1

Busse, M. R., Lacetera, N., Pope, D. G., Silva-Risso, J. and Sydnor, J. R. (2013). Estimating the effect of salience in wholesale and retail car markets. American Economic Review, 103 (3), 575-579. 2

Chetty, R., Looney, A. and Kroft, K. (2009). Salience and taxation: Theory and evidence. American Economic Review, 99(4), 1145-1177. 1, 3

DellaVigna, S. (2009). Psychology and economics: Evidence from the field. Journal of Economic Literature, 47(2), 315-372. 1, 11, 12, 20

Englmaier, F., Schmöller, A. and Stowasser, T. (2016). Price discontinuities in online auctions - Disentangling search costs and limited attention. Working Paper. 21

Finkelstein, A. (2009). Ez tax: Tax salience and tax rates. Quarterly Journal of Economics, 124(3), 969-1010. 1, 3

Gilbert, T., Kogan, S., Lochstoer, L. A. and Ozyildirim, A. (2012). Investor inattention and the market impact of summary statistics. Management Science, 58 (2), 336-350. 3

Lacetera, N., Pope, D. G. and Sydnor, H. (2012). Heuristic thinking and limited attention in the car market. American Economic Review, 102(5), 2206-2236. 1, 2, 11, 14, 15, 16, 19, 20, xv

Lee, D. S. and Lemieux, T. (2010). Regression discontinuity designs in economics. Journal of Economic Literature, 48(2), 281-355. 10, viii

Lewis, G. (2011). Asymmetric information, adverse selection and online disclosure: The case of ebay motors. American Economic Review, 101 (4), 1535-1546. 2

Luca, M. (2016). Reviews, reputation, and revenue: The case of yelp.com. HBS Working Paper. 3, 20

Malmendier, U. (2016). The bidder's curse: Reply. American Economic Review, Vol. 106(4), 1195-1213. 21

— and Lee, Y. H. (2011). The bidder's curse. American Economic Review, 101(2), 749-787. 1, 2

Pope, D. G. (2009). Reacting to rankings: Evidence from "America's best hospitals". Journal of Health Economics, Vol. 28(6), pp. 1154-1165. 2 
Schneider, H. S. (2016). The bidder's curse: Comment. American Economic Review, Vol. 106(4), pp. 1182-1194. 2, 21

Simon, H. A. (1955). A behavioral model of rational choice. Quarterly Journal of Economics, Vol. 69(1), pp. 99-118. 1

Tadelis, S. and Zettelmeyer, F. (2015). Information disclosure as a matching mechanism: Theory and evidence from a field experiment. American Economic Review, 105 (2), 886-905. 2 


\section{Online Appendix for "Price Discontinuities in an Online Market for Used Cars" by Florian Englmaier, Arno Schmöller, and Till Stowasser}

Online Appendix A contains additional tables and figures that complement the data description in Section 2.2 and the graphical analysis in Section 3. Online Appendix B contains the robustness analysis with respect to results in the vintage dimension, as summarized in Section 4. Online Appendix C contains the robustness analysis with respect to results in the mileage dimension, as summarized in Section 4. Online Appendix D contains the robustness analysis with respect to the horserace analysis, as summarized in Section 4. 


\section{A Additional tables and figures}

Table A.1. Overview of car-model generations

\begin{tabular}{lclc}
\hline Make and model & Model generation & & Production span \\
\hline Audi A4 & B6 & $\begin{array}{l}\text { (limousine) } \\
\text { (estate) }\end{array}$ & $\begin{array}{l}10 / 2000-11 / 2004 \\
09 / 2001-11 / 2004 \\
\end{array}$ \\
& B7 & $\begin{array}{l}\text { (limousine) } \\
\text { (estate) }\end{array}$ & $11 / 2004-11 / 2007$ \\
& & & $04 / 1998-11 / 2004$ \\
\hline BMW 3 & E46 & (limousine) & $12 / 2004-09 / 2008$ \\
& E90 & (estate) & $06 / 2005-09 / 2008$ \\
\hline Mercedes A Class & W168 & & $09 / 1997-09 / 2004$ \\
& W169 & & $10 / 2004-04 / 2012$ \\
\hline Opel Astra & G & & $02 / 1998-01 / 2004$ \\
& H & & $02 / 2004-10 / 2007$ \\
\hline VW Golf & IV & & $10 / 1997-09 / 2003$ \\
& V & & $10 / 2003-07 / 2008$ \\
\hline
\end{tabular}

Notes: Depicted are the production spans of model generations for all cars in our sample. 
Figure A.1. Average car prices by car age

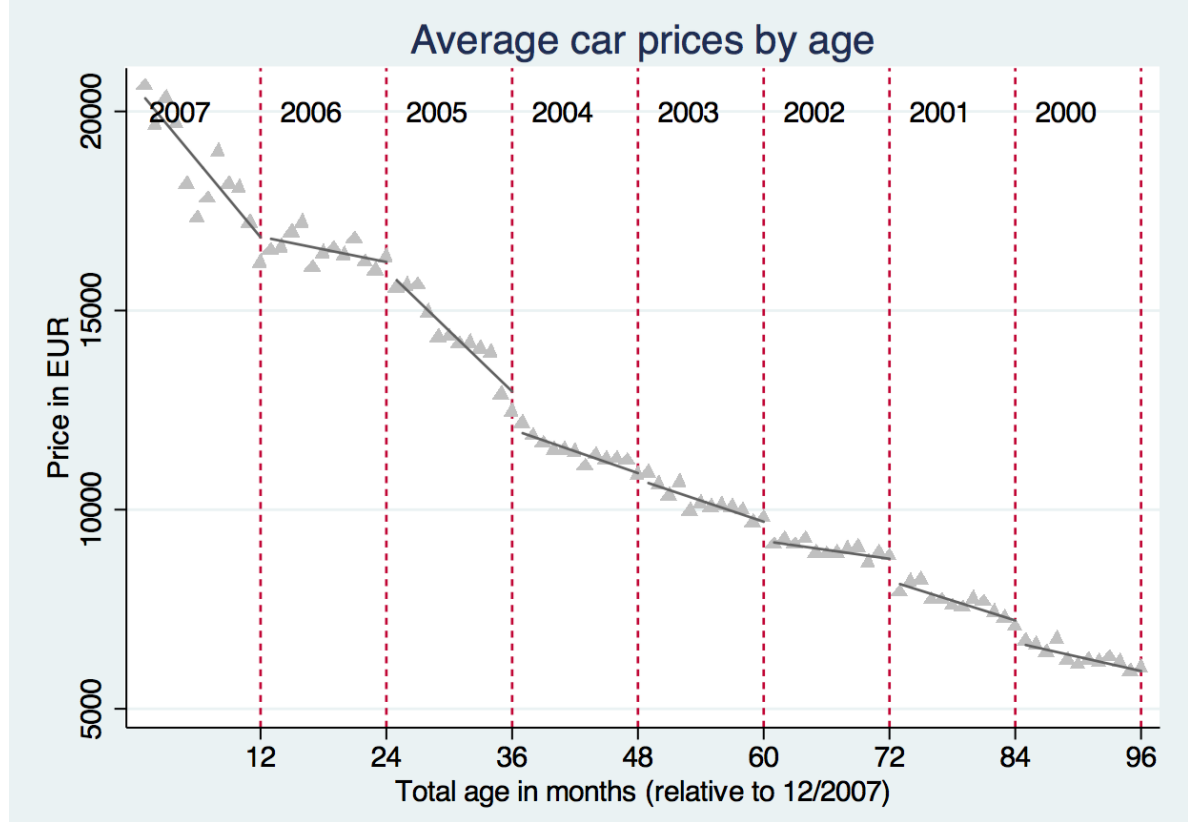

Notes: Plotted are average car prices as a function of car age measured on a monthly basis. Age is measured relative to the date of first registration $12 / 2007$. Vertical dashed lines indicate vintage (or registration year) thresholds. Solid lines represent linear fits within each vintage.

Figure A.2. Average car prices by car mileage

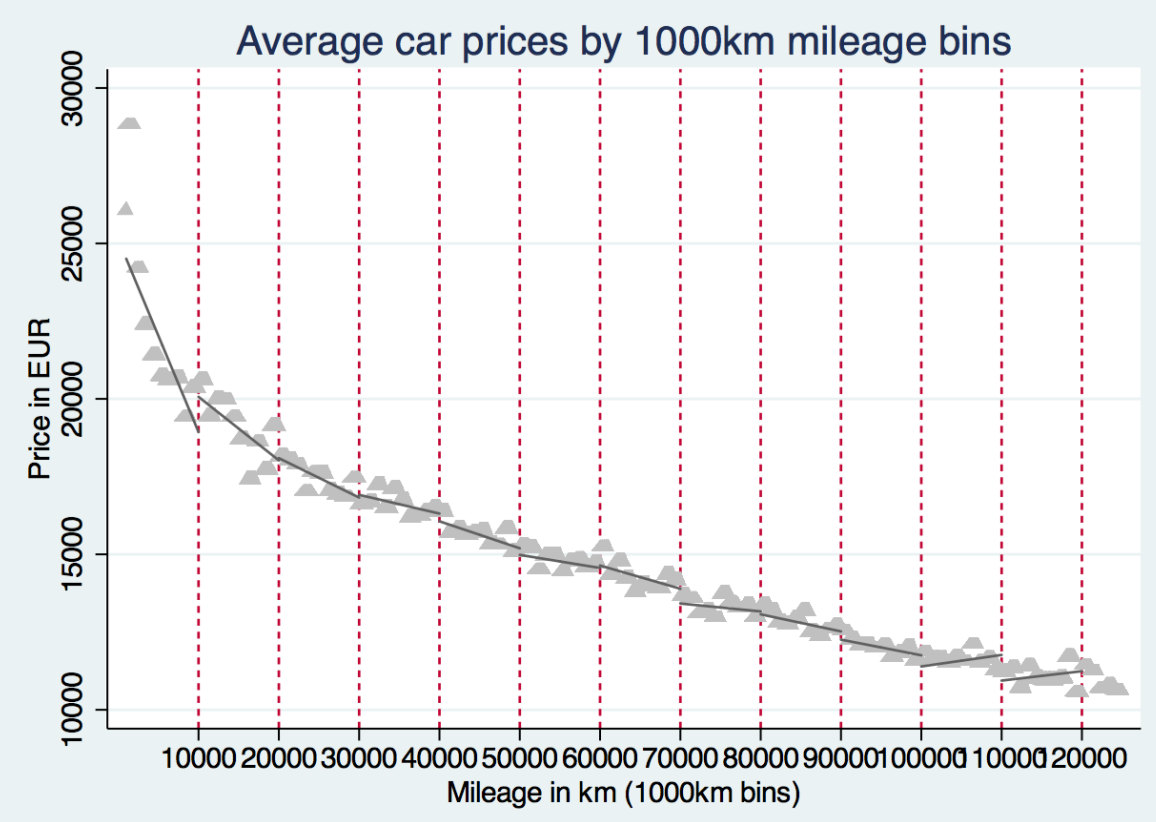

Notes: Plotted are average car prices as a function of car mileage measured in 1,000-km bins. Vertical dashed lines indicate 10,000-km mileage thresholds. Solid lines represent linear fits between thresholds. 


\section{B Robustness analysis: Vintage dimension}

\section{B.1 Potential empirical pitfalls}

Observable heterogeneity around thresholds

To assure that our results are not driven by differing car populations around the thresholds, we check whether January and December cars are comparable with respect to their average mileage (Figure B.1), their average horsepower (Figure B.2), their average fuel type (Figure B.3), and the composition of seller types (private versus commercials sellers) (Figure B.4). These raw-data plots show somewhat erratic but certainly unsystematic patterns, which suggests that the observed price discontinuities are not driven by changes in the underlying market composition.

Figure B.1. Average car mileage by car age

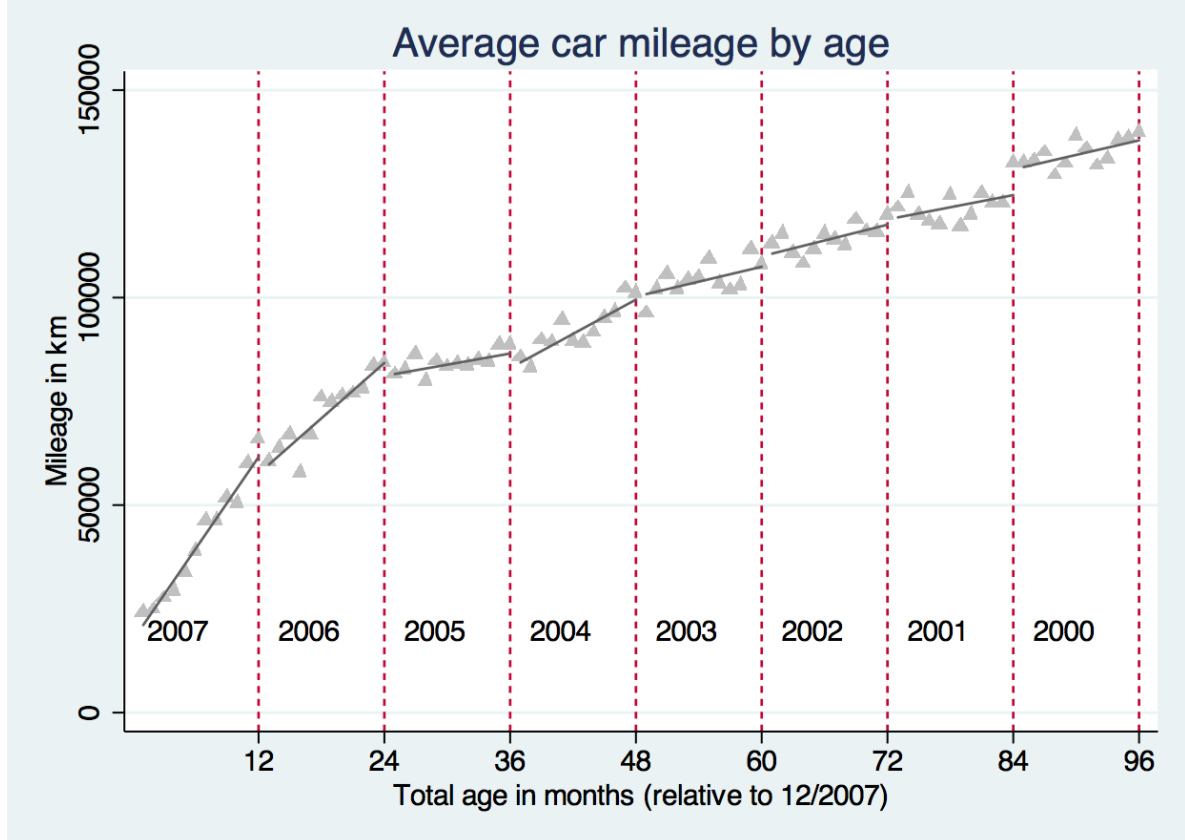

Notes: Plotted is the average mileage of traded cars as a function of car age measured on a monthly basis. Age is measured relative to the date of first registration 12/2007. Vertical dashed lines indicate vintage (or registration year) thresholds. Solid lines represent linear fits within each vintage. 
Figure B.2. Average horsepower by car age

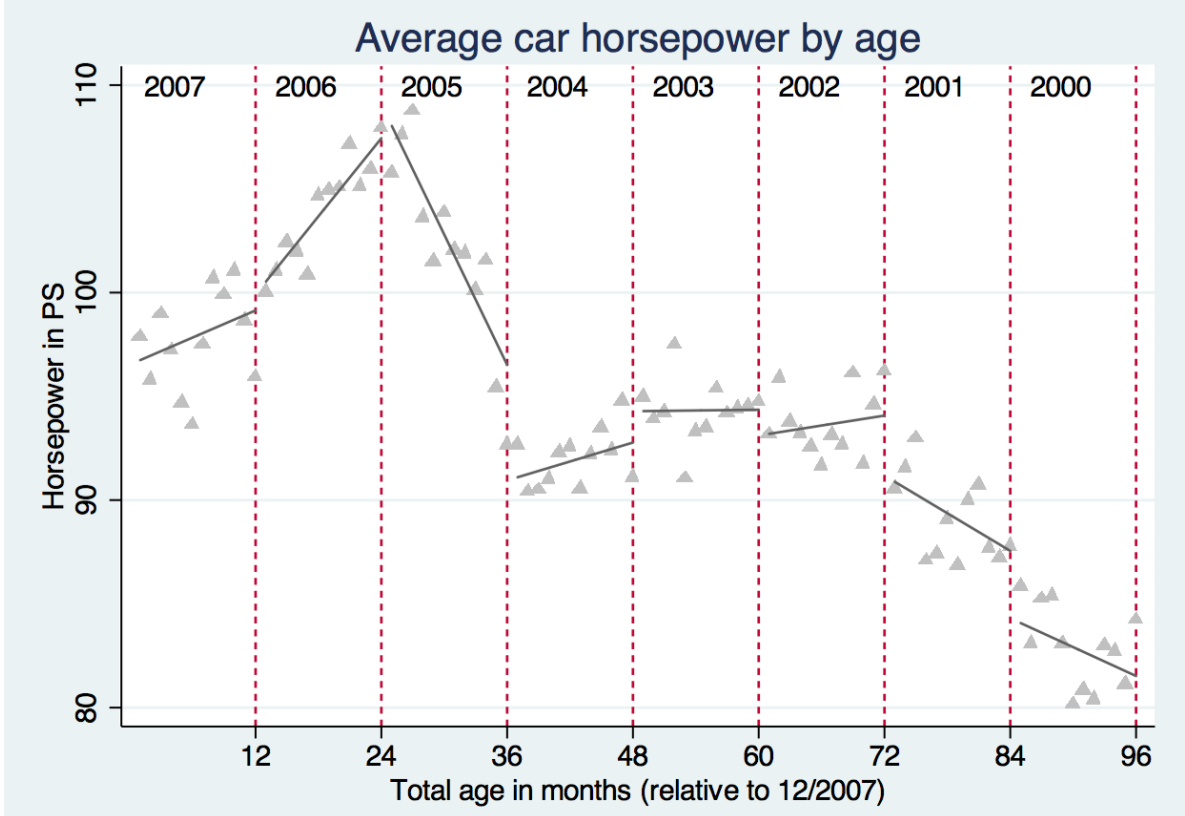

Notes: Plotted is the average horsepower of traded cars as a function of car age measured on a monthly basis. Age is measured relative to the date of first registration 12/2007. Vertical dashed lines indicate vintage (or registration year) thresholds. Solid lines represent linear fits within each vintage.

Figure B.3. Share of cars with regular fuel by car age

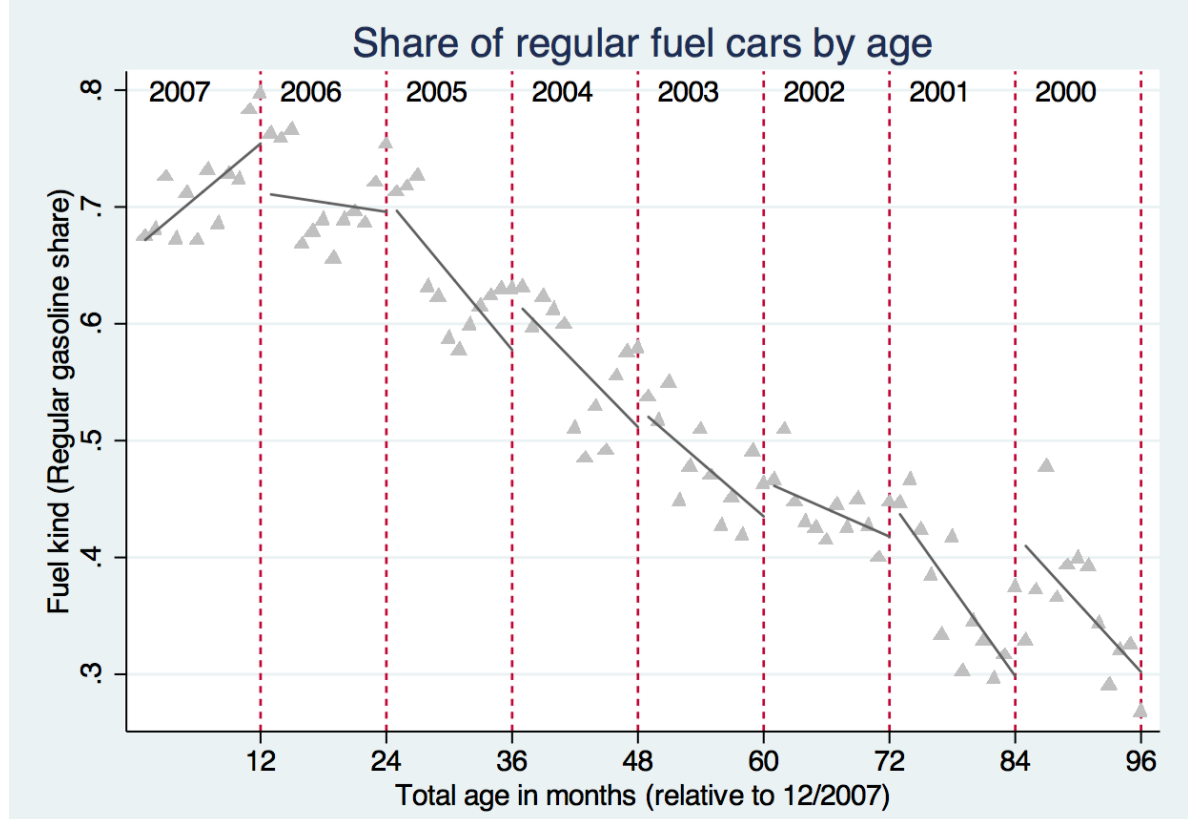

Notes: Plotted is the share of traded cars with regular fuel as a function of car age measured on a monthly basis. Age is measured relative to the date of first registration 12/2007. Vertical dashed lines indicate vintage (or registration year) thresholds. Solid lines represent linear fits within each vintage. 
Figure B.4. Share of private sellers by car age

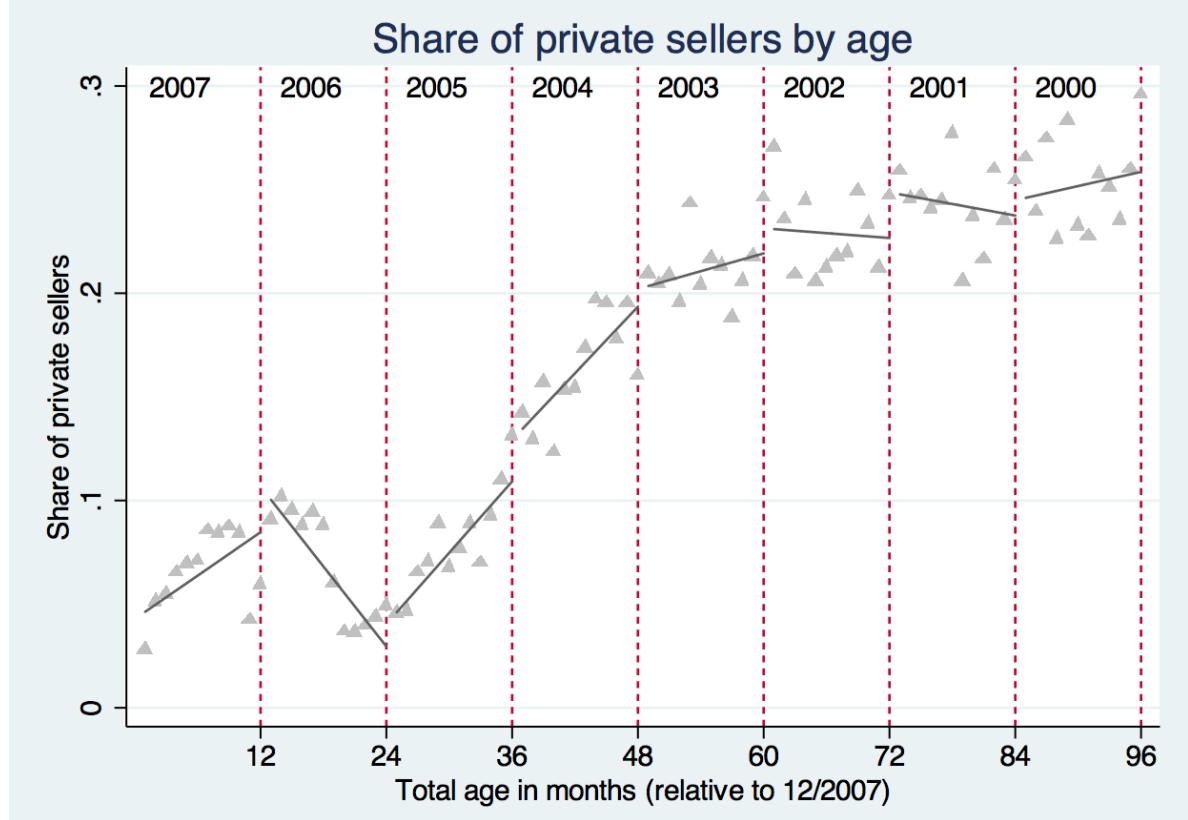

Notes: Plotted is the share of cars offered by private sellers as a function of car age measured on a monthly basis. Age is measured relative to the date of first registration 12/2007. Vertical dashed lines indicate vintage (or registration year) thresholds. Solid lines represent linear fits within each vintage.

\section{Placebo tests}

In another important consistency check we perform placebo tests by creating indicators for artificial year thresholds and testing whether these are associated with discontinuities as well. Even though we observe significant coefficients for a few placebo thresholds, these are unsystematic, both with respect to their sign and their size. Results for three different placebo tests that move the vintage thresholds to the other three end-of-quarter months - March, June, and September - can be found in Table B.1. 
Table B.1. Robustness analysis (vintage): Placebo thresholds

Dependent variable: Car prices

Regression coefficients

(Robust standard errors in brackets)

\begin{tabular}{|c|c|c|c|}
\hline & (1) & (2) & (3) \\
\hline \multicolumn{4}{|l|}{ Indicator for... } \\
\hline \multirow{2}{*}{...FR before 2007} & -151.3 & $636.2 * * *$ & $-588.5 * *$ \\
\hline & $(110.4)$ & (146.0) & (181.0) \\
\hline \multirow[t]{2}{*}{...FR before 2006} & 79.7 & $455.0 * * *$ & $466.8 * * *$ \\
\hline & (55.5) & (75.9) & (90.3) \\
\hline \multirow[t]{2}{*}{...FR before 2005} & $-263.0 * * *$ & $-305.1 * * *$ & $-224.5 * * *$ \\
\hline & $(57.3)$ & (59.6) & $(57.4)$ \\
\hline \multirow[t]{2}{*}{...FR before 2004} & $229.6 * *$ & 18.0 & $195.0 * *$ \\
\hline & $(77.4)$ & $(73.9)$ & (65.3) \\
\hline \multirow[t]{2}{*}{...FR before 2003} & $225.5 * *$ & 177.7 & $374.6 * * *$ \\
\hline & $(73.6)$ & $(94.1)$ & (93.7) \\
\hline \multirow[t]{2}{*}{...FR before 2002} & -131.6 & -8.5 & $185.2^{*}$ \\
\hline & $(81.7)$ & $(89.4)$ & $(82.4)$ \\
\hline \multirow[t]{2}{*}{...FR before 2001} & $-313.6 * * *$ & $-207.2^{*}$ & 104.6 \\
\hline & (85.3) & $(98.4)$ & $(93.6)$ \\
\hline Car-age polynomial & $\mathrm{X}$ & $\mathrm{X}$ & $\mathrm{X}$ \\
\hline Controls for car features & $\mathrm{X}$ & $\mathrm{X}$ & $\mathrm{X}$ \\
\hline Controls for model updates & $\mathrm{X}$ & $X$ & $\mathrm{X}$ \\
\hline Car-model fixed effects & $\mathrm{X}$ & $\mathrm{X}$ & $\mathrm{X}$ \\
\hline Placebo threshold month & March & June & September \\
\hline $\mathrm{R}^{2}$ & 0.8586 & 0.8588 & 0.8588 \\
\hline $\mathrm{N}$ & 50,872 & 50,872 & 50,872 \\
\hline
\end{tabular}

Notes: Depicted are estimates for $\beta_{y}^{v}$ (see Section 3.1) when applied to the respective placebo thresholds. FR stands for "first registered". All regressions include the original non-placebo December thresholds, for which estimates do not significantly change. Control variables are the same as in the main empirical specification. Robust standard errors are stated in brackets. *, **, and $* * *$ indicate statistical significance at the $5 \%$, the $1 \%$, and the $0.1 \%$ level, respectively. 
Table B.2. Robustness analysis (vintage): Log-linearization

Dependent variable: Log of car prices

Regression coefficients

(Robust standard errors in brackets)

(1)

(2)

(3)

(4)

(5)

\begin{tabular}{|c|c|c|c|c|c|}
\hline Indicator for... & & & & & \\
\hline ...FR before 2007 & $0.024 *$ & -0.008 & $-0.041 * * *$ & $-0.032 * * *$ & $-0.043 * * *$ \\
\hline & $(0.010)$ & $(0.006)$ & $(0.006)$ & $(0.005)$ & $(0.005)$ \\
\hline ...FR before 2006 & $-0.027 * * *$ & $-0.034 * * *$ & $-0.049 * * *$ & $-0.033 * * *$ & $-0.043 * * *$ \\
\hline & $(0.008)$ & $(0.004)$ & $(0.004)$ & $(0.003)$ & $(0.004)$ \\
\hline ...FR before 2005 & $-0.087 * * *$ & $-0.044 * * *$ & $-0.045 * * *$ & $-0.034 * * *$ & $-0.039 * * *$ \\
\hline & $(0.008)$ & $(0.005)$ & $(0.005)$ & $(0.004)$ & $(0.004)$ \\
\hline ...FR before 2004 & 0.017 & $-0.025 * *$ & $-0.020 * *$ & $-0.034 * * *$ & $-0.018 * *$ \\
\hline & $(0.011)$ & $(0.007)$ & $(0.007)$ & $(0.006)$ & $(0.006)$ \\
\hline ...FR before 2003 & -0.014 & $-0.017^{*}$ & $-0.020 * *$ & -0.008 & -0.007 \\
\hline & $(0.011)$ & $(0.007)$ & $(0.008)$ & $(0.006)$ & $(0.006)$ \\
\hline ...FR before 2002 & $-0.087 * * *$ & $-0.052 * * *$ & $-0.060 * * *$ & $-0.046 * * *$ & $-0.053 * * *$ \\
\hline & $(0.013)$ & $(0.009)$ & $(0.009)$ & $(0.008)$ & $(0.008)$ \\
\hline ...FR before 2001 & $-0.111 * * *$ & $-0.075 * * *$ & $-0.076 * * *$ & $-0.070 * * *$ & $-0.071^{* * *}$ \\
\hline & $(0.013)$ & $(0.009)$ & $(0.010)$ & $(0.008)$ & $(0.008)$ \\
\hline Car-age polynomial & $\mathrm{X}$ & $\mathrm{X}$ & $\mathrm{X}$ & $\mathrm{X}$ & $\mathrm{X}$ \\
\hline Controls for car features & & $\mathrm{X}$ & $\mathrm{X}$ & $\mathrm{X}$ & $\mathrm{X}$ \\
\hline Controls for model updates & & & $\mathrm{X}$ & & $\mathrm{X}$ \\
\hline Car-model fixed effects & & & & $\mathrm{X}$ & $\mathrm{X}$ \\
\hline $\mathrm{R}^{2}$ & 0.5340 & 0.8450 & 0.8416 & 0.8941 & 0.8945 \\
\hline $\mathrm{N}$ & 63,340 & 50,872 & 50,872 & 50,872 & 50,872 \\
\hline
\end{tabular}

Notes: Depicted are estimates for $\beta_{y}^{v}$ (see Section 3.1) after taking the log of car prices. Car age is controlled for by a fifth-order polynomial (chosen based on the Akaike Information Criterion Test). Car features include all car characteristics listed in Table 1. Robust standard errors are stated in brackets. * $* *$, and $* * *$ indicate statistical significance at the $5 \%$, the $1 \%$, and the $0.1 \%$ level, respectively.

\section{B.2 Robustness to changes in the main specification}

\section{Log-linearization}

Since the distribution of prices is right-skewed (recall Figure 6), a sensible robustnesscheck is to log-linearize Regression 1. As results in Table B.2 reveal, this modification produces results that are even more consistent than those from our main specification, which is particularly reassuring given the long right tail in prices. 


\section{Alternative model-update indicators}

In our main specification, we classify a car as having undergone a model update if its date of first registration was more than three months after factories switched production. Our results are robust to varying definitions of model-update indicators, which suggests that the potential measurement error when assigning the model-generation information is unlikely to be harmful. Table B. 3 collects the results for the following dummy definitions that we used for robustness analysis: ${ }^{30}$

- D1: Model-generation indicator (measuring fixed effects for each model generation) imposing no insecurity: We treat all cars registered one month or later after the official model switch as being a new model.

- D2: Model-generation indicator (measuring fixed effects for each model generation) with five-months insecurity window: Like D1 but we treat the model status of cars registered within three months after a model switch as unknown. Effectively, these cars are not used to identify our model.

- D3: Model-update dummy imposing no insecurity: Takes on the value of one if a model update happened in a given month.

- D4: Model-update dummy, with five-months insecurity window: Like D3 but the five months after the introduction of a new model are also labeled as a modelupdate month.

\section{Alternative car-age polynomials}

A key identifying assumption of any research-discontinuity design is that the continuous relationship between the forcing variable (here: car age) and the outcome variable (here: car price) is adequately captured by the polynomial function $f(\cdot)$. Since this assumption is inherently untestable, the literature (see e.g., Lee and Lemieux, 2010) stresses that results should be robust to varying polynomial functions in order to be credible. As can be seen in Table B.4, this is indeed the case, as our key results stay stable even when lower-order and higher-order polynomials than those endorsed by the Akaike Information-Criterion Test are used.

\footnotetext{
${ }^{30}$ We have also experimented with smaller and larger insecurity windows (three to six months) but omitted these results to save space. Results are very similar.
} 
Table B.3. Robustness analysis (vintage): Alternative model-update indicators

Dependent variable: Car prices

Regression coefficients

(Robust standard errors in brackets)
(1)
(2)
(3)
(4)
(5)
(6)
(7)

(8)

\begin{tabular}{|c|c|c|c|c|c|c|c|c|}
\hline \multicolumn{9}{|l|}{ Indicator for... } \\
\hline \multirow{2}{*}{...FR before 2007} & 44.3 & -56.5 & 126.4 & -72.0 & 25.9 & -33.8 & -152.8 & -158.6 \\
\hline & (108.3) & (89.4) & (108.4) & (90.7) & (107.7) & (91.8) & (108.2) & (91.9) \\
\hline \multirow[t]{2}{*}{...FR before 2006} & \multicolumn{8}{|c|}{$-603.2 * * *-636.3 * * *-524.5 * * *-549.3 * * *-581.0 * * *-557.4 * * *-833.6 * * *-736.7 * * *$} \\
\hline & (65.7) & $(54.0)$ & $(66.0)$ & $(54.9)$ & $(65.8)$ & (55.3) & $(66.9)$ & $(56.0)$ \\
\hline \multirow[t]{2}{*}{...FR before 2005} & $-725.7 * * *$ & -83.4 & \multicolumn{6}{|c|}{$-505.9 * * *-352.0 * * *-751.0 * * *-643.2 * * *-547.9 * * *-492.1 * * *$} \\
\hline & (62.7) & $(52.8)$ & $(65.3)$ & (57.3) & (64.3) & (56.1) & $(62.8)$ & $(54.0)$ \\
\hline \multirow[t]{2}{*}{...FR before 2004} & -122.1 & 70.8 & 51.1 & 53.3 & $-192.6^{*}$ & -134.3 & 146.4 & 111.6 \\
\hline & $(86.0)$ & $(76.6)$ & $(92.7)$ & $(84.4)$ & $(88.1)$ & $(78.5)$ & $(87.6)$ & $(77.9)$ \\
\hline \multirow[t]{2}{*}{...FR before 2003} & -29.2 & $-314.9 * * *$ & -29.7 & -86.3 & $-177.9 *$ & 20.6 & -67.0 & 96.5 \\
\hline & $(74.9)$ & (70.1) & $(76.3)$ & $(70.8)$ & (76.9) & $(69.1)$ & $(76.8)$ & $(68.9)$ \\
\hline \multirow[t]{2}{*}{...FR before 2002} & $-417.2 * * *$ & $-202.4 *$ & \multicolumn{2}{|c|}{$-468.8 * * *-236.0 * *$} & $-399.4 * * *$ & $-297.1 * *$ & $-568.3 * * *$ & $-418.8 * * *$ \\
\hline & (86.1) & (84.6) & (87.6) & (84.3) & (88.4) & (82.4) & (88.2) & (83.3) \\
\hline \multirow[t]{2}{*}{...FR before 2001} & $-379.4 * * *$ & 83.6 & \multicolumn{2}{|c|}{$-389.8 * * *-542.5 * * *$} & $-445.7 * * *$ & $-340.2 * *$ & $-402.9 * * *$ & $-308.9 * * *$ \\
\hline & (91.4) & $(91.4)$ & (98.0) & (97.3) & (94.1) & (91.9) & (93.2) & (91.7) \\
\hline Car-age polynomial & $\mathrm{X}$ & $\mathrm{X}$ & $\mathrm{X}$ & $\mathrm{X}$ & $\mathrm{X}$ & $\mathrm{X}$ & $\mathrm{X}$ & $\mathrm{X}$ \\
\hline Controls for car features & $\mathrm{X}$ & $\mathrm{X}$ & $\mathrm{X}$ & $\mathrm{X}$ & $\mathrm{X}$ & $\mathrm{X}$ & $\mathrm{X}$ & $\mathrm{X}$ \\
\hline Car-model fixed effects & & $\mathrm{X}$ & & $\mathrm{X}$ & & $\mathrm{X}$ & & $\mathrm{X}$ \\
\hline Controls for model updates & D1 & D1 & D2 & D2 & D3 & D3 & D4 & D4 \\
\hline $\mathrm{R}^{2}$ & 0.8179 & 0.8650 & 0.8203 & 0.8621 & 0.8169 & 0.8587 & 0.8163 & 0.8583 \\
\hline $\mathrm{N}$ & 50,872 & 50,872 & 50,872 & 50,872 & 50,872 & 50,872 & 50,872 & 50,872 \\
\hline
\end{tabular}

Notes: Depicted are estimates for $\beta_{y}^{v}$ (see Section 3.1) for varying model-update indicators. Mainspecification benchmark: A car is classified as a new model if its date of first registration is more than three months after an official model launch. D1: Model-generation indicator imposing no insecurity (all cars registered at least one month after an official model launch are classified as a new model). D2: Model-generation indicator with five-months insecurity window (like D1 but the model status of cars registered within five months after a model launch is treated as unknown). D3: Modelupdate indicator imposing no insecurity (takes on the value of one if a model update happened in a given month). D4: Model-update dummy, with five-months insecurity window (like D3 but the three months after a market launch are also labeled as a model-update month). Car age is controlled for by a fifth-order polynomial (chosen based on the Akaike Information Criterion Test). Car features include all car characteristics listed in Table 1 . Robust standard errors are stated in brackets. *, **, and $* * *$ indicate statistical significance at the $5 \%$, the $1 \%$, and the $0.1 \%$ level, respectively. 
Table B.4. Robustness analysis (vintage): Alternative car-age polynomials

Dep. Variable: Car price

(1)

\begin{tabular}{|c|c|c|c|c|c|}
\hline \multicolumn{6}{|l|}{ Indicator for... } \\
\hline \multirow[t]{2}{*}{...FR before 2007} & -136.7 & 45.1 & $-325.7 * *$ & $-606.1 * * *$ & $-677.9 * * *$ \\
\hline & (93.8) & (105.9) & (116.6) & (130.5) & (141.1) \\
\hline \multirow[t]{2}{*}{...FR before 2006} & $-276.8 * * *$ & $-654.7 * * *$ & $-575.8 * * *$ & $-436.3 * * *$ & $-397.0 * * *$ \\
\hline & $(51.1)$ & $(60.4)$ & $(64.5)$ & (66.6) & $(70.9)$ \\
\hline \multirow[t]{2}{*}{...FR before 2005} & $-512.7 * * *$ & $-908.7 * * *$ & $-306.0 * * *$ & $-330.0 * * *$ & $-389.4 * * *$ \\
\hline & $(60.2)$ & (63.8) & $(69.8)$ & $(69.2)$ & $(72.0)$ \\
\hline \multirow[t]{2}{*}{...FR before 2004} & $-898.5^{* * *}$ & $-514.2 * * *$ & $-205.7^{*}$ & $-499.4 * * *$ & $-465.3 * * *$ \\
\hline & $(76.2)$ & (72.6) & (86.6) & (97.9) & (96.4) \\
\hline \multirow[t]{2}{*}{...FR before 2003} & $-266.7 * * *$ & $-199.9 * * *$ & $-464.8 * * *$ & $-334.4 * * *$ & $-269.0 * *$ \\
\hline & $(62.8)$ & $(75.5)$ & $(87.1)$ & $(87.1)$ & $(92.0)$ \\
\hline \multirow[t]{2}{*}{...FR before 2002} & -160.6 & -100.6 & $-319.2^{* * *}$ & -119.8 & $-203.7^{*}$ \\
\hline & (68.3) & (81.3) & (88.1) & (93.4) & (96.7) \\
\hline \multirow[t]{2}{*}{...FR before 2001} & 114.2 & $-208.7^{*}$ & $-344.5 * * *$ & -23.2 & $-272.5^{*}$ \\
\hline & (91.1) & $(89.9)$ & (102.0) & $(112.1)$ & (116.7) \\
\hline Order of age polynomial & 3rd & 4th & 6th & 7th & 8th \\
\hline Controls for car features & $\mathrm{X}$ & $\mathrm{X}$ & $\mathrm{X}$ & $\mathrm{X}$ & $\mathrm{X}$ \\
\hline Controls for model updates & $\mathrm{X}$ & $\mathrm{X}$ & $\mathrm{X}$ & $\mathrm{X}$ & $\mathrm{X}$ \\
\hline Car-model fixed effects & $\mathrm{X}$ & $\mathrm{X}$ & $\mathrm{X}$ & $\mathrm{X}$ & $\mathrm{X}$ \\
\hline $\mathrm{R}^{2}$ & 0.8594 & 0.8185 & 0.8178 & 0.8179 & 0.8179 \\
\hline $\mathrm{N}$ & 50,872 & 50,872 & 50,872 & 50,872 & 50,872 \\
\hline
\end{tabular}

Notes: Depicted are estimates for $\beta_{y}^{v}$ (see Section 3.1) for varying car-age polynomials. The mainspecification benchmark is a fifth-order polynomial (chosen based on the Akaike Information Criterion Test). Robust standard errors are stated in brackets. *, **, and *** indicate statistical significance at the $5 \%$, the $1 \%$, and the $0.1 \%$ level, respectively. 


\section{Robustness analysis: Mileage dimension}

\section{C.1 Potential empirical pitfalls}

Observable heterogeneity around thresholds

To assure that our results are not driven by differing car populations around the thresholds, we check whether cars to the left and to the right of 10,000-km marks are comparable with respect to their average mileage (see Figure C.1), their average horsepower (see Figure C.2), their average fuel type (see Figure C.3), and the composition of seller types (private versus commercials sellers) (see Figure C.4). As was the case for the vintage thresholds, these raw data plots show erratic but unsystematic patterns, which suggests that the observed price discontinuities are not driven by changes in the underlying market composition.

Figure C.1. Average car age by car mileage

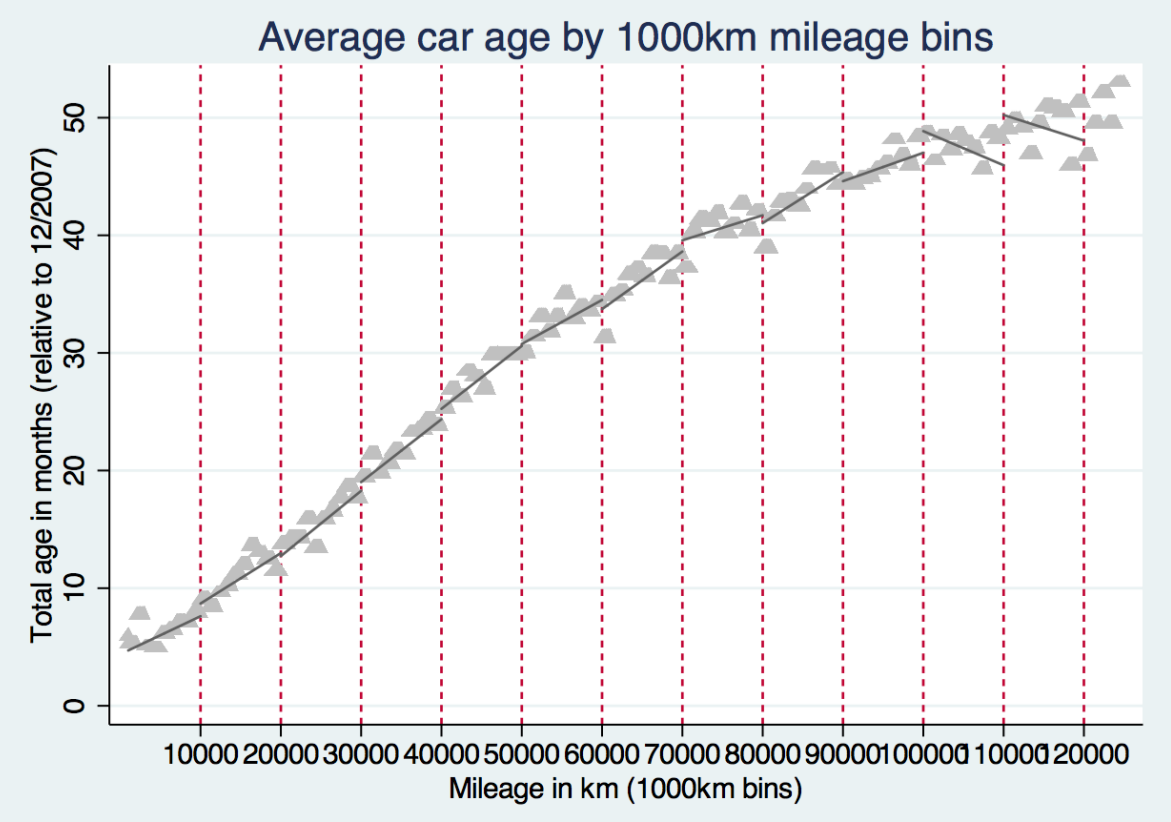

Notes: Plotted is the average age of traded cars as a function of car mileage measured in 1,000-km bins. Vertical dashed lines indicate 10,000-km thresholds. Solid lines represent linear fits between thresholds. 
Figure C.2. Average horsepower by car mileage

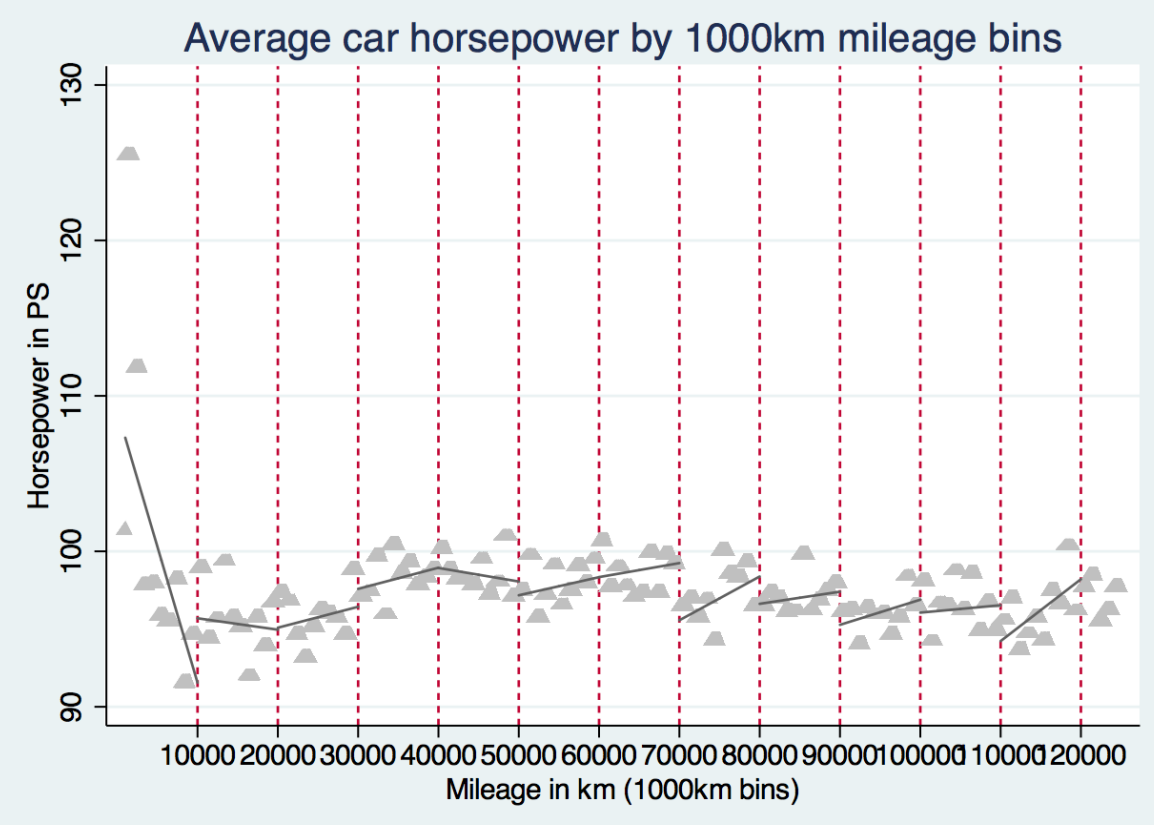

Notes: Plotted is the average horsepower of traded cars as a function of car mileage measured in 1,000-km bins. Vertical dashed lines indicate 10,000-km thresholds. Solid lines represent linear fits between thresholds.

Figure C.3. Share of cars with regular fuel by car mileage

Share of regular fuel cars by $1000 \mathrm{~km}$ mileage bins

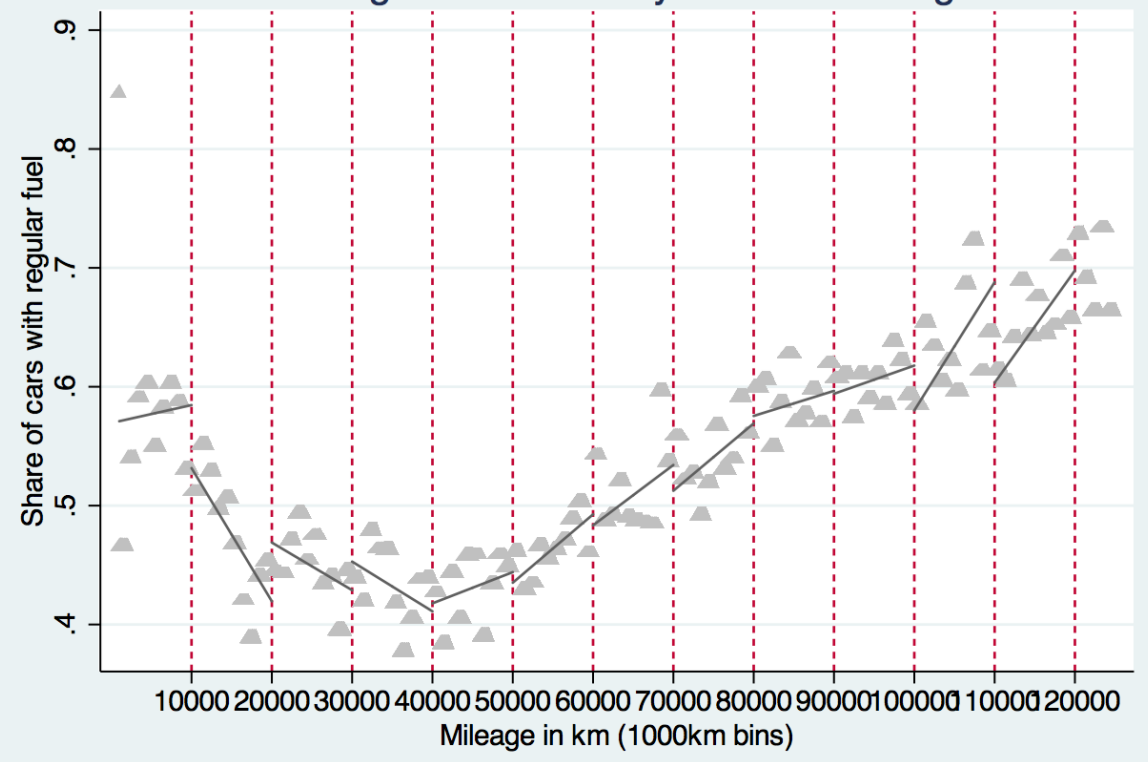

Notes: Plotted is the share of traded cars with regular fuel as a function of car mileage measured in 1,000-km bins. Vertical dashed lines indicate $10,000-\mathrm{km}$ thresholds. Solid lines represent linear fits between thresholds. 
Figure C.4. Share of private sellers by car mileage

\section{Share of private sellers by $1000 \mathrm{~km}$ mileage bins}

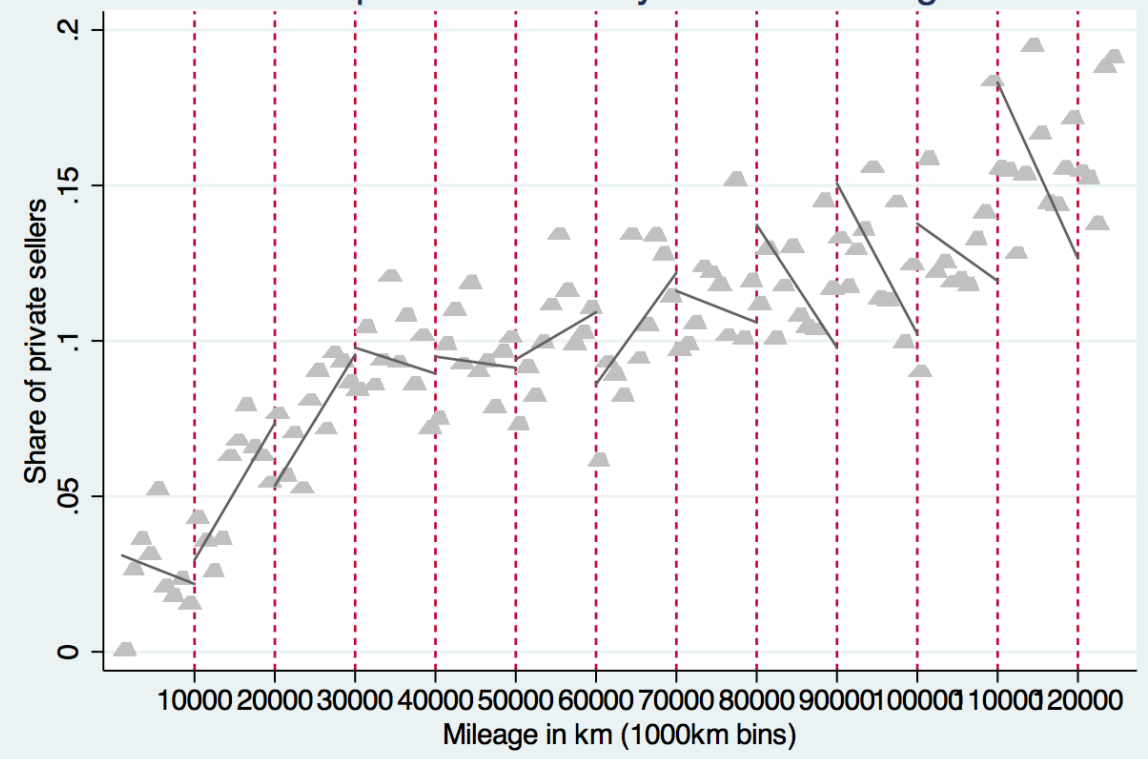

Notes: Plotted is the share of cars offered by private sellers as a function of car mileage measured in 1,000-km bins. Vertical dashed lines indicate 10,000-km thresholds. Solid lines represent linear fits between thresholds.

\section{Placebo test}

For our placebo test in the mileage dimension, we convert odometer readings from kilometers to US miles and check for discontinuities in the converted data at 10,000mile thresholds. Given that Germany exclusively uses the metric system, US miles thresholds should be irrelevant even if heuristics play a role in decision making. As is apparent from Table C.1, all but the very first 10,000-mile placebo threshold are statistically indistinguishable from zero, which is in line with expectations. 
Table C.1. Robustness analysis (mileage): Placebo thresholds

Dependent variable: Car prices

$$
\text { Regression coefficients }
$$

(Robust standard errors in brackets)

(1)

\begin{tabular}{|c|c|}
\hline \multirow{2}{*}{...more than $10 \mathrm{~K}$ miles } & $-709.0 * * *$ \\
\hline & $(176.7)$ \\
\hline \multirow[t]{2}{*}{...more than $20 \mathrm{~K}$ miles } & -97.1 \\
\hline & $(131.3)$ \\
\hline \multirow[t]{2}{*}{...more than $30 \mathrm{~K}$ miles } & 1.6 \\
\hline & $(107.9)$ \\
\hline \multirow{2}{*}{...more than $40 \mathrm{~K}$ miles } & -181.0 \\
\hline & $(79.3)$ \\
\hline \multirow[t]{2}{*}{...more than $50 \mathrm{~K}$ miles } & -105.6 \\
\hline & $(161.2)$ \\
\hline \multirow[t]{2}{*}{...more than $60 \mathrm{~K}$ miles } & -71.4 \\
\hline & $(74.3)$ \\
\hline \multirow[t]{2}{*}{...more than $70 \mathrm{~K}$ miles } & -45.3 \\
\hline & (86.3) \\
\hline \multirow{2}{*}{...more than $80 \mathrm{~K}$ miles } & 34.9 \\
\hline & $(126.8)$ \\
\hline \multirow[t]{2}{*}{...more than $90 \mathrm{~K}$ miles } & -101.6 \\
\hline & $(100.1)$ \\
\hline \multirow[t]{2}{*}{...more than $100 \mathrm{~K}$ miles } & -35.4 \\
\hline & $(85.1)$ \\
\hline Car-mileage polynomial & $\mathrm{X}$ \\
\hline Controls for car features & $\mathrm{X}$ \\
\hline Controls for model updates & $\mathrm{X}$ \\
\hline Car-model fixed effects & $\mathrm{X}$ \\
\hline $\mathrm{R}^{2}$ & 0.8172 \\
\hline $\mathrm{N}$ & 50,872 \\
\hline \multicolumn{2}{|c|}{$\begin{array}{l}\text { Notes: Depicted are estimates for } \beta_{y}^{m} \text { (see Section } 3.2 \text { ) after converting the } \\
\text { mileage data from kilometers to US miles. All regressions include the origi- } \\
\text { nal } 10,000-\mathrm{km} \text { thresholds, for which estimates do not significantly change. } \\
\text { Control variables are the same as in the main empirical specification. Ro- } \\
\text { bust standard errors are stated in brackets. *, } * * \text {, and } * * * \text { indicate statistical } \\
\text { significance at the } 5 \% \text {, the } 1 \% \text {, and the } 0.1 \% \text { level, respectively. }\end{array}$} \\
\hline
\end{tabular}




\section{C.2 Robustness to changes in the main specification}

\section{Log-linearization}

As results in Table C.2 reveal, log-linearization of Regression 2 is not innocuous and even reverses results for some $10,000-\mathrm{km}$ thresholds. This pattern is puzzling, since discontinuities in the mileage dimension have been convincingly documented to be systematic and sizable by Lacetera et al. (2012). However, we are certainly not inclined to call their findings into question but rather attribute the lack of robustness to the concerns of measurement error in our mileage data.

\section{Alternative model-update indicators}

As was the case for the vintage discontinuities, our mileage results are robust to varying definitions of model-update indicators. This suggests that the potential measurement error when assigning the model-generation information is unlikely to be harmful. Results in Table C.3 are for the same definitions of alternative indicators as described in Section B.2.

\section{Alternative car-age polynomials}

As was the case with log-linearization, results in the mileage domain are somewhat sensitive to using car-age polynomials of orders higher than three, whereas orders of one, two (the main-specification benchmark), and three work fine (see Table C.4). However, note that specifications that accommodate polynomials of orders higher than three appear to suffer from multicollinearity and that our statistical software fails to return the F-Test statistic, which suggests that results are in line with expectations, as long as the econometric model is not misspecified. 
Table C.2. Robustness analysis (mileage): Log-linearization

Dependent variable: Log of car prices

Regression coefficients

(Robust standard errors in brackets)

(1)

(2)

(3)

(4)

(5)

\begin{tabular}{|c|c|c|c|c|c|}
\hline ...more than $10 \mathrm{~K} \mathrm{~km}$ & $\begin{array}{c}-0.057 * \\
(0.011)\end{array}$ & $\begin{array}{c}0.044^{* * *} \\
(0.008)\end{array}$ & $\begin{array}{c}0.041^{* * *} \\
(0.006)\end{array}$ & $\begin{array}{c}0.060 * * * \\
(0.005)\end{array}$ & $\begin{array}{c}0.058 * * * \\
(0.005)\end{array}$ \\
\hline ...more than $20 \mathrm{~K} \mathrm{~km}$ & $\begin{array}{c}-0.033 * * * \\
(0.009)\end{array}$ & $\begin{array}{c}0.029 * * * \\
(0.006)\end{array}$ & $\begin{array}{c}0.029 * * * \\
(0.004)\end{array}$ & $\begin{array}{c}0.034^{* * *} \\
(0.003)\end{array}$ & $\begin{array}{c}0.035 * * * \\
(0.004)\end{array}$ \\
\hline ...more than $30 \mathrm{~K} \mathrm{~km}$ & $\begin{array}{c}-0.001 \\
(0.008)\end{array}$ & $\begin{array}{c}0.050 * * * \\
(0.005)\end{array}$ & $\begin{array}{c}0.050 * * * \\
(0.005)\end{array}$ & $\begin{array}{c}0.052 \% * * \\
(0.004)\end{array}$ & $\begin{array}{c}0.051 * * * \\
(0.004)\end{array}$ \\
\hline ...more than $40 \mathrm{~K} \mathrm{~km}$ & $\begin{array}{c}-0.015^{*} \\
(0.008)\end{array}$ & $\begin{array}{c}0.034^{* * *} \\
(0.005)\end{array}$ & $\begin{array}{c}0.033 * * \\
(0.007)\end{array}$ & $\begin{array}{c}0.031^{* * *} \\
(0.006)\end{array}$ & $\begin{array}{c}0.030 * * * \\
(0.006)\end{array}$ \\
\hline ...more than $50 \mathrm{~K} \mathrm{~km}$ & $\begin{array}{c}-0.016 * \\
(0.008)\end{array}$ & $\begin{array}{l}0.007 \\
(0.004)\end{array}$ & $\begin{array}{l}0.008 \\
(0.008)\end{array}$ & $\begin{array}{l}0.005 \\
(0.006)\end{array}$ & $\begin{array}{l}0.006 \\
(0.006)\end{array}$ \\
\hline ...more than $60 \mathrm{~K} \mathrm{~km}$ & $\begin{array}{c}0.0107 \\
(0.008)\end{array}$ & $\begin{array}{l}0.006 \\
(0.004)\end{array}$ & $\begin{array}{l}0.006 \\
(0.009)\end{array}$ & $\begin{array}{l}0.003 \\
(0.008)\end{array}$ & $\begin{array}{l}0.003 \\
(0.008)\end{array}$ \\
\hline ...more than $70 \mathrm{~K} \mathrm{~km}$ & $\begin{array}{c}-0.030 * * * * \\
(0.008)\end{array}$ & $\begin{array}{c}-0.004 \\
(0.004)\end{array}$ & $\begin{array}{c}-0.004 \\
(0.009)\end{array}$ & $\begin{array}{c}-0.006 \\
(0.008)\end{array}$ & $\begin{array}{c}-0.006 \\
(0.008)\end{array}$ \\
\hline ...more than $80 \mathrm{~K} \mathrm{~km}$ & $\begin{array}{l}0.006 \\
(0.008)\end{array}$ & $\begin{array}{l}0.000 \\
(0.004)\end{array}$ & $\begin{array}{l}0.000 \\
(0.009)\end{array}$ & $\begin{array}{c}-0.005 \\
(0.008)\end{array}$ & $\begin{array}{c}-0.005^{*} \\
(0.008)\end{array}$ \\
\hline ...more than $90 \mathrm{~K} \mathrm{~km}$ & $\begin{array}{c}-0.024 * * * \\
(0.008)\end{array}$ & $\begin{array}{c}-0.017 * * * \\
(0.004)\end{array}$ & $\begin{array}{c}-0.017 * * * \\
(0.009)\end{array}$ & $\begin{array}{c}-0.017 * * * \\
(0.008)\end{array}$ & $\begin{array}{c}-0.017^{* * *} \\
(0.008)\end{array}$ \\
\hline ...more than $100 \mathrm{~K} \mathrm{~km}$ & $\begin{array}{l}0.006 \\
(0.009)\end{array}$ & $\begin{array}{l}-0.002 \\
(0.005)\end{array}$ & $\begin{array}{c}-0.002 \\
(0.010)\end{array}$ & $\begin{array}{c}-0.005 \\
(0.008)\end{array}$ & $\begin{array}{c}-0.005 \\
(0.008)\end{array}$ \\
\hline Car-mileage polynomial & $\mathrm{X}$ & $\mathrm{X}$ & $\mathrm{X}$ & $\mathrm{X}$ & $\mathrm{X}$ \\
\hline Controls for car features & & $\mathrm{X}$ & $\mathrm{X}$ & $\mathrm{X}$ & $\mathrm{X}$ \\
\hline Controls for model updates & & & $\mathrm{X}$ & & $\mathrm{X}$ \\
\hline Car-model fixed effects & & & & $\mathrm{X}$ & $\mathrm{X}$ \\
\hline $\mathrm{R}^{2}$ & 0.2930 & 0.8208 & 0.8215 & 0.8692 & 0.8699 \\
\hline $\mathrm{N}$ & 63,340 & 50,872 & 50,872 & 50,872 & 50,872 \\
\hline
\end{tabular}

Notes: Depicted are estimates for $\beta_{y}^{m}$ (see Section 3.2) after taking the log of car prices. All regressions include the original 10,000-km thresholds, for which estimates do not significantly change. Control variables are the same as in the main empirical specification. Robust standard errors are stated in brackets. *, **, and *** indicate statistical significance at the $5 \%$, the $1 \%$, and the $0.1 \%$ level, respectively. 
Table C.3. Robustness analysis (mileage): Alternative model-update indicators

\begin{tabular}{|c|c|c|c|c|c|c|c|c|}
\hline \multicolumn{9}{|c|}{ Dependent variable: Log of car prices } \\
\hline & \multicolumn{8}{|c|}{$\begin{array}{l}\text { Regression coefficients } \\
\text { (Robust standard errors in brackets) }\end{array}$} \\
\hline & (1) & $(2)$ & (3) & (4) & (5) & (6) & $(7)$ & $(8)$ \\
\hline \multicolumn{9}{|l|}{ Indicator for... } \\
\hline \multirow[t]{2}{*}{...more than $10 \mathrm{~K} \mathrm{~km}$} & $-937.4 * * *$ & $-1,143.9 * * *$ & $*-981.6 * * *$ & $-1,024.6^{* * * *}$ & $-1,048.4 * *$ & $*-926.0 * * *$ & $-1,024.7 * * *$ & $*-903.8 * * *$ \\
\hline & (173.9) & $(157.2)$ & (173.5) & $(158.0)$ & $(170.7)$ & (158.9) & (173.6) & $(160.7)$ \\
\hline \multirow[t]{2}{*}{...more than $20 \mathrm{~K} \mathrm{~km}$} & $-762.3 * * *$ & $-788.6 * * *$ & $-775.0 * * *$ & $-756.6 * * *$ & $-739.2 * * *$ & $-722.1 * * *$ & $-784.0 * * *$ & $-754.0 * * *$ \\
\hline & $(109.0)$ & (92.9) & $(109.2)$ & (94.1) & (105.4) & (93.9) & (108.4) & (95.9) \\
\hline \multirow{2}{*}{...more than $30 \mathrm{~K} \mathrm{~km}$} & $-322.2 * * *$ & $-455.7 * * *$ & $-355.0 * * *$ & $-378.9^{* * *}$ & $-353.5^{* * *}$ & $-356.8 * * *$ & $-369.9 * * *$ & $-367.9 * * *$ \\
\hline & (82.9) & (69.9) & (83.5) & (70.7) & (81.4) & $(70.5)$ & (82.9) & (71.5) \\
\hline \multirow[t]{2}{*}{...more than $40 \mathrm{~K} \mathrm{~km}$} & $-351.3 * * *$ & $-480.9 * * *$ & $-374.2 * * *$ & $-442.3^{* * *}$ & $-367.3 * * *$ & $-419.2^{* * *}$ & $-380.9 * * *$ & $-428.5 * * *$ \\
\hline & $(69.5)$ & (58.0) & (70.6) & $(59.0)$ & (69.1) & (58.7) & (69.7) & (59.2) \\
\hline \multirow[t]{2}{*}{...more than $50 \mathrm{~K} \mathrm{~km}$} & $-131.0 *$ & $-153.3 * *$ & $-160.1^{* *}$ & $-144.7 * *$ & $-145.5^{*}$ & $-167.1^{* *}$ & $-146.9 *$ & $-168.3 * *$ \\
\hline & $(60.3)$ & (50.4) & (61.5) & (51.7) & $(60.6)$ & (51.7) & $(60.5)$ & (51.6) \\
\hline \multirow[t]{2}{*}{...more than $60 \mathrm{~K} \mathrm{~km}$} & $-208.1^{* * *}$ & $-214.4 * * *$ & $-226.7^{* * *}$ & $-214.3^{* * *}$ & $-203.7 * * *$ & $-235.2 * * *$ & $-209.1 * * *$ & $-240.3 * * *$ \\
\hline & (57.3) & (47.6) & (58.5) & $(49.0)$ & (57.8) & (49.1) & (57.6) & (48.9) \\
\hline \multirow[t]{2}{*}{...more than $70 \mathrm{~K} \mathrm{~km}$} & $-220.3 * * *$ & $-218.1^{* * *}$ & $-271.5 * * *$ & $-229.3^{* * *}$ & $-223.1 * * *$ & $-236.6 * * *$ & $-224.8 * * *$ & $-237.6 * * *$ \\
\hline & (54.9) & (45.3) & (56.2) & $(47.0)$ & (55.5) & $(47.0)$ & (55.2) & $(46.8)$ \\
\hline \multirow[t]{2}{*}{...more than $80 \mathrm{~K} \mathrm{~km}$} & $-144.0 * *$ & $-201.8 * * *$ & $-134.4 *$ & $-187.5^{* * *}$ & $-142.1 * *$ & $-211.1 * * *$ & $-138.8 * *$ & $-209.8 * * *$ \\
\hline & (52.5) & (43.7) & (53.9) & $(45.5)$ & (53.1) & $(45.4)$ & (52.9) & $(45.2)$ \\
\hline \multirow[t]{2}{*}{...more than $90 \mathrm{~K} \mathrm{~km}$} & $-285.6 * * *$ & $-257.3 * * *$ & $-292.0 * * *$ & $-249.9^{* * *}$ & $-284.5 * * *$ & $-281.3^{* * * *}$ & $-285.3 * * *$ & $-282.6 * * *$ \\
\hline & $(50.2)$ & $(42.8)$ & (51.6) & $(44.5)$ & (50.9) & $(44.0)$ & (50.7) & (43.8) \\
\hline \multirow[t]{2}{*}{...more than $100 \mathrm{~K} \mathrm{~km}$} & $-122.9 *$ & $-182.4 * * *$ & $-146.0 * *$ & $-165.9 * * *$ & $-122.9 *$ & $-169.9 * * *$ & $-128.5^{*}$ & $-174.2 * * *$ \\
\hline & $(52.5)$ & $(45.4)$ & $(54.5)$ & $(47.6)$ & $(53.3)$ & $(46.5)$ & $(53.0)$ & $(46.4)$ \\
\hline Car-mileage polynomial & $\mathrm{X}$ & $\mathrm{X}$ & $\mathrm{X}$ & $\mathrm{X}$ & $\mathrm{X}$ & $\mathrm{X}$ & $\mathrm{X}$ & $\mathrm{X}$ \\
\hline Controls for car features & $\mathrm{X}$ & $\mathrm{X}$ & $\mathrm{X}$ & $\mathrm{X}$ & $\mathrm{X}$ & $\mathrm{X}$ & $\mathrm{X}$ & $\mathrm{X}$ \\
\hline Controls for model updates & D1 & D1 & D2 & D2 & D3 & D3 & D4 & D4 \\
\hline Car-model fixed effects & & $\mathrm{X}$ & & $\mathrm{X}$ & & $\mathrm{X}$ & & $\mathrm{X}$ \\
\hline $\mathrm{R}^{2}$ & 0.8160 & 0.8651 & 0.8173 & 0.8623 & 0.8160 & 0.8581 & 0.8148 & 0.8574 \\
\hline $\mathrm{N}$ & 50,872 & 50,872 & 48,572 & 48,572 & 50,872 & 50,872 & 50,872 & 50,872 \\
\hline
\end{tabular}

Notes: Depicted are estimates for $\beta_{y}^{m}$ (see Section 3.2) for varying model-update indicators. Mainspecification benchmark: A car is classified as a new model if its date of first registration is more than three months after an official model launch. D1: Model-generation indicator imposing no insecurity (all cars registered at least one month after an official model launch are classified as a new model). D2: Model-generation indicator with five-months insecurity window (like D1 but the model status of cars registered within five months after a model launch is treated as unknown). D3: Modelupdate indicator imposing no insecurity (takes on the value of one if a model update happened in a given month). D4: Model-update dummy, with five-months insecurity window (like D3 but the three months after a market launch are also labeled as a model-update month). Car mileage is controlled for by a second-order polynomial (chosen based on the Akaike Information Criterion Test). Car features include all car characteristics listed in Table 1. Robust standard errors are stated in brackets. $*{ }^{* *}$, and $* * *$ indicate statistical significance at the $5 \%$, the $1 \%$, and the $0.1 \%$ level, respectively. 
Table C.4. Robustness analysis (mileage): Alternative car-mileage polynomials

Dep. Variable: Car price
(1)
(2)
(3)
(4)

(5)

\begin{tabular}{|c|c|c|c|c|c|}
\hline \multicolumn{6}{|l|}{ Indicator for... } \\
\hline \multirow[t]{2}{*}{...more than $10 \mathrm{~K} \mathrm{~km}$} & $-1,039.5 * * *$ & $-804.1 * * *$ & $-585.7^{* * *}$ & $-476.5 * *$ & $999.2 * *$ \\
\hline & (161.6) & (178.0) & (178.0) & (183.3) & $(313.4)$ \\
\hline \multirow[t]{2}{*}{...more than $20 \mathrm{~K} \mathrm{~km}$} & $-864.1 * * *$ & $-558.2 * * *$ & $-337.6^{* * *}$ & -233.1 & $392.6^{*}$ \\
\hline & $(98.9)$ & (117.6) & (118.6) & $(126.9)$ & $(184.4)$ \\
\hline \multirow{2}{*}{...more than $30 \mathrm{~K} \mathrm{~km}$} & $-463.1 * * *$ & -143.2 & 67.9 & 161.7 & 214.3 \\
\hline & $(75.3)$ & (93.6) & (93.8) & (101.9) & $(127.2)$ \\
\hline \multirow[t]{2}{*}{...more than $40 \mathrm{~K} \mathrm{~km}$} & $-524.7 * * *$ & $-175.4^{*}$ & 19.7 & 100.2 & -151.8 \\
\hline & $(62.6)$ & $(81.7)$ & $(82.5)$ & $(90.2)$ & $(115.0)$ \\
\hline \multirow[t]{2}{*}{...more than $50 \mathrm{~K} \mathrm{~km}$} & $-249.5 * * *$ & 83.6 & $254.4 * * *$ & $-319.2 * * *$ & -20.3 \\
\hline & $(55.5)$ & (71.6) & (71.9) & (77.8) & (96.0) \\
\hline \multirow[t]{2}{*}{...more than $60 \mathrm{~K} \mathrm{~km}$} & $-369.1 * * *$ & -38.7 & 114.7 & $167.7^{*}$ & -138.7 \\
\hline & $(55.3)$ & (67.7) & $(67.8)$ & $(72.3)$ & $(84.0)$ \\
\hline \multirow[t]{2}{*}{...more than $70 \mathrm{~K} \mathrm{~km}$} & $-352.6 * * *$ & -39.0 & 103.9 & $148.0^{*}$ & -99.2 \\
\hline & (53.3) & (65.0) & $(64.9)$ & $(68.4)$ & $(78.6)$ \\
\hline \multirow[t]{2}{*}{...more than $80 \mathrm{~K} \mathrm{~km}$} & $-344.9 * * *$ & 10.7 & $131.4^{*}$ & $163.8 * *$ & 6.4 \\
\hline & (51.9) & $(60.7)$ & (60.4) & (62.6) & (75.5) \\
\hline \multirow[t]{2}{*}{...more than $90 \mathrm{~K} \mathrm{~km}$} & $-412.2 * * *$ & $-126.2 *$ & -15.9 & 9.0 & -96.4 \\
\hline & $(50.0)$ & $(58.0)$ & (57.3) & (58.9) & (75.6) \\
\hline \multirow{2}{*}{...more than $100 \mathrm{~K}$} & $-297.5 * * *$ & -11.6 & 77.6 & 93.7 & 30.8 \\
\hline & $(51.2)$ & $(58.2)$ & (57.7) & (58.5) & (74.9) \\
\hline Order of mileage polynomial & $1 s t$ & $3 r d$ & 4th & 5 th & 6th \\
\hline Controls for car features & $\mathrm{X}$ & $\mathrm{X}$ & $\mathrm{X}$ & $\mathrm{X}$ & $\mathrm{X}$ \\
\hline Controls for model updates & $\mathrm{X}$ & $\mathrm{X}$ & $\mathrm{X}$ & $\mathrm{X}$ & $\mathrm{X}$ \\
\hline Car-model fixed effects & $\mathrm{X}$ & $\mathrm{X}$ & $\mathrm{X}$ & $\mathrm{X}$ & $\mathrm{X}$ \\
\hline $\mathrm{R}^{2}$ & 0.8605 & 0.8183 & 0.8184 & 0.8184 & 0.8178 \\
\hline $\mathrm{N}$ & 50,872 & 50,872 & 50,872 & 50,872 & 50,872 \\
\hline
\end{tabular}

Notes: Depicted are estimates for $\beta_{y}^{m}$ (see Section 3.2) for varying car-mileage polynomials. The main-specification benchmark is a second-order polynomial (chosen based on the Akaike Information Criterion Test). Robust standard errors are stated in brackets. *, **, and $* * *$ indicate statistical significance at the $5 \%$, the $1 \%$, and the $0.1 \%$ level, respectively. 


\section{Robustness analysis: Horserace}

As a final robustness exercise, we implement a horserace specification by controlling for mileage and vintage thresholds at the same time. Results in Table D.1 show that both discontinuities exist independently of one another. Not only do effects in either dimension survive, but especially the vintage discontinuities are even slightly more pronounced. 
Table D.1. Robustness analysis: Horserace between vintage and mileage discontinuities

Dependent variable: Car prices

Regression coefficients

(Robust standard errors in brackets)

(1)

(3)

\begin{tabular}{|c|c|c|c|}
\hline Indicator for... & & & \\
\hline ...older than 2007 & $\begin{array}{c}-221.4 * \\
(91.8)\end{array}$ & & $\begin{array}{c}-265.7 * * \\
(90.1)\end{array}$ \\
\hline ...older than 2006 & $\begin{array}{c}-780.3^{* * *} \\
(56.6)\end{array}$ & & $\begin{array}{c}-805.9 * * * \\
(55.5)\end{array}$ \\
\hline ...older than 2005 & $\begin{array}{c}-609.2^{* * *} \\
(54.9)\end{array}$ & & $\begin{array}{c}-610.0 * * * \\
(54.1)\end{array}$ \\
\hline ...older than 2004 & $\begin{array}{c}-3.7 \\
(77.7)\end{array}$ & & $\begin{array}{c}7.9 \\
(71.9)\end{array}$ \\
\hline ...older than 2003 & $\begin{array}{c}44.3 \\
(68.9)\end{array}$ & & $\begin{array}{c}56.4 \\
(67.5)\end{array}$ \\
\hline ...older than 2002 & $\begin{array}{c}-437.9 * * * \\
(83.5)\end{array}$ & & $\begin{array}{c}-441.3 * * * \\
(83.2)\end{array}$ \\
\hline ...older than 2001 & $\begin{array}{c}-345.1^{* * *} \\
(91.7)\end{array}$ & & $\begin{array}{c}-385.8 * * * \\
(90.6)\end{array}$ \\
\hline ...more than $10 \mathrm{~K} \mathrm{~km}$ & & $\begin{array}{c}-905.9 * * * \\
(160.5)\end{array}$ & $\begin{array}{c}-719.3 * * \\
(159.5)\end{array}$ \\
\hline ...more than $20 \mathrm{~K} \mathrm{~km}$ & & $\begin{array}{c}-749.2^{* * *} \\
(95.7)\end{array}$ & $\begin{array}{c}-550.9 * * * \\
(93.4)\end{array}$ \\
\hline ...more than $30 \mathrm{~K} \mathrm{~km}$ & & $\begin{array}{c}-368.8 * * * \\
(71.4)\end{array}$ & $\begin{array}{c}-140.5^{*} \\
(69.8)\end{array}$ \\
\hline ...more than $40 \mathrm{~K} \mathrm{~km}$ & & $\begin{array}{c}-428.4 * * * \\
(59.2)\end{array}$ & $\begin{array}{c}-218.2^{* * *} \\
(56.9)\end{array}$ \\
\hline ...more than $50 \mathrm{~K} \mathrm{~km}$ & & $\begin{array}{c}-163.9 * * * \\
(51.6)\end{array}$ & $\begin{array}{l}-84.2 \\
(49.9)\end{array}$ \\
\hline ...more than $60 \mathrm{~K} \mathrm{~km}$ & & $\begin{array}{c}-242.9 * * * \\
(48.9)\end{array}$ & $\begin{array}{c}-174.2^{* * *} \\
(47.6)\end{array}$ \\
\hline ...more than $70 \mathrm{~K} \mathrm{~km}$ & & $\begin{array}{c}-234.6^{* * *} \\
(46.8)\end{array}$ & $\begin{array}{c}-190.7^{* * *} \\
(45.7)\end{array}$ \\
\hline ...more than $80 \mathrm{~K} \mathrm{~km}$ & & $\begin{array}{c}-212.9 * * * \\
(45.2)\end{array}$ & $\begin{array}{c}-210.8^{* * *} \\
(44.0)\end{array}$ \\
\hline ...more than $90 \mathrm{~K} \mathrm{~km}$ & & $\begin{array}{c}-281.8^{* * *} \\
(43.8)\end{array}$ & $\begin{array}{c}-290.3 * * * \\
(42.8)\end{array}$ \\
\hline ...more than $100 \mathrm{~K} \mathrm{~km}$ & & $\begin{array}{c}-169.6 * * * \\
(46.4)\end{array}$ & $\begin{array}{c}-185.0 * * * \\
(45.3)\end{array}$ \\
\hline Car-age polynomial & $\mathrm{X}$ & & $\mathrm{X}$ \\
\hline Car-mileage polynomial & & $\mathrm{X}$ & $\mathrm{X}$ \\
\hline Controls for car features & $\mathrm{X}$ & $\mathrm{X}$ & $\mathrm{X}$ \\
\hline Controls for model updates & $\mathrm{X}$ & $\mathrm{X}$ & $\mathrm{X}$ \\
\hline Car-model fixed effects & $\mathrm{X}$ & $\mathrm{X}$ & $\mathrm{X}$ \\
\hline $\mathrm{R}^{2}$ & 0.8584 & 0.8575 & 0.8661 \\
\hline $\mathrm{N}$ & 50,872 & 50,872 & 50,872 \\
\hline
\end{tabular}

Notes: Depicted are estimates for $\beta_{y}^{v}$ and $\beta_{y}^{m}$ when jointly controlling for car vintage and car mileage (see Sections 3.1 and 3.2). Control variables are the same as in the main empirical specification. Robust standard errors are stated in brackets. *,**, and *** indicate statistical significance at the $5 \%$, the $1 \%$, and the $0.1 \%$ level, respectively. 